Article

\title{
Analysis of Thermal Anomalies in Volcanic Areas Using Multiscale and Multitemporal Monitoring: Vulcano Island Test Case
}

\author{
Malvina Silvestri ${ }^{1, *}\left(\mathbb{D}\right.$, Federico Rabuffi $^{2}$, Antonino Pisciotta $^{3}$, Massimo Musacchio ${ }^{1}{ }^{(0)}$, \\ Iole Serena Diliberto $^{3} \mathbb{D}$, Claudia Spinetti ${ }^{1} \mathbb{D}$, Valerio Lombardo ${ }^{1}$, Laura Colini ${ }^{1}$ and \\ Maria Fabrizia Buongiorno ${ }^{1}$ \\ 1 Istituto Nazionale di Geofisica e Vulcanologia, Osservatorio Nazionale Terremoti, Via di Vigna Murata 605, \\ 00143 Roma, Italy; massimo.musacchio@ingv.it (M.M.); claudia.spinetti@ingv.it (C.S.); \\ valerio.lombardo@ingv.it (V.L.); laura.colini@ingv.it (L.C.); fabrizia.buongiorno@ingv.it (M.F.B.) \\ 2 Freelance, 00185 Rome, Italy; fed.rabuffi@gmail.com \\ 3 Istituto Nazionale di Geofisica e Vulcanologia, Sezione di Palermo, Via Ugo la Malfa 153, 90146 Palermo, \\ Italy; fabio.pisciotta@ingv.it (A.P.); iole.diliberto@ingv.it (I.S.D.) \\ * Correspondence: malvina.silvestri@ingv.it; Tel.: +39-06-51860-732
}

Received: 14 November 2018; Accepted: 8 January 2019; Published: 11 January 2019

\begin{abstract}
Surface temperatures derived by 208 ASTER and L8 satellite imagery were analysed to test multiscale and multitemporal capability through available sets of thermal data to support the volcanic monitoring of Vulcano Island in Italy. The analysis of thermal historical series derived by ASTER and L8 shows that two are the main thermally active areas: La Fossa crater and the mud pool of Fangaia. In this work we aimed to assess the correlation between the satellite-retrieved temperatures with those measured during the daytime ground field campaign conducted within the same time period and, in particular cases, simultaneously. Moreover, nighttime data acquired by an airborne and field campaign were processed with the same methodology applied to satellite data for a multiscale approach verification. Historical meteorological data acquired from a weather station were also considered. Statistically significant correlations were observed between nighttime acquisitions and meteorological data. Correlations were also significant for temperature measured during the airborne campaign, while differences up to $50 \%$ with daytime acquisition during the ground field campaigns were observed. The analysis of the results suggests that within nighttime data acquisition, differences between satellite-derived temperatures and ground temperature measurements are considerably reduced; therefore nighttime data acquisition is recommended to detect thermal anomalies.
\end{abstract}

Keywords: remote sensing; long term monitoring; thermal measurements; satellite measurements validation

\section{Introduction}

The aim of volcanic surveillance is the interpretation of the observed data in order to highlight changes of volcano activity and to define the potential risks for human health and activities. The geochemical monitoring procedures are involved in activities of volcanic observatories and include the detection and quantification of fluids that are continuously released from hydrothermal and/or magmatic sources both during quiescence and eruptive periods [1-6].

The thermal energy released by a volcanic system is a parameter of primary importance for the monitoring of volcanic activity. During inter-eruptive periods, the thermal emissions by hydrothermal fluids, the emission of steam through the fumaroles and even the diffuse heat release from the ground are a significant part of the total energy released by the volcano. This slow and restless energy release 
is, in the long term, comparable to the seismic release of volcano-tectonic origin [6-11]. For many years, the amount of convective energy released on the surface of the Island of Vulcano has been estimated by direct samplings and measurements of the fumaroles of La Fossa cone [7,12], and the exhaling temperatures and the steam flows in some sample points have been measured. Thanks to the long-term monitoring, the time variations of fumaroles temperatures showed a combination of periodic characters and episodic anomalies, related to both geochemical changes from the source, and external perturbation, due to the variability of the atmospheric conditions [13-15]. Some major increases of fumaroles temperature were highlighted a few months before the increase in local seismic activity $[11,13]$ and even months before the related deformation phases which affected the northern flank of the active cone [16]. The volcanic system is very dynamic and it is affected by volcano tectonic processes which could change the areal distribution and intensity of thermal anomalies. This process requires an accurate thermal mapping of the ground, which needs to be extended beyond the area where there is major evidence of fumarole release. The InfraRed (IR) optical sensors promise good results for extended thermal mapping, once detection limits are ascertained and correlated with ground measurements.

Remote sensing allows us to observe the Earth surface at a large scale, with a defined acquisition frequency, and with a favorable cost-benefit ratio; moreover, it allows us to acquire data in areas that are difficult to reach. Current satellite missions, providing imagery in the Thermal InfraRed (TIR) spectral region at high spatial resolution, give the possibility to estimate the surface temperature and highlight the main surface changes, potentially related to the buried energy sources.

To improve the systematic use of satellite data in the monitoring procedures of Volcanic Observatories, suitable integration and validation strategies are needed in current satellite missions to provide TIR data with a spectral range suitable for detecting low thermal anomalies but with ground spatial resolution which is too coarse; conversely, direct monitoring could instead validate satellite measurements $[1,6,7,10-16]$.

The improved thermal surveillance of active volcanoes enhances hazard assessment and substantially contributes to understanding the modulation of endogenic heat released through the hydrothermal processes, throughout all the volcanic phases of activity. The systematic monitoring highlights changes of volcanic phenomenology and contributes to define the related risk for human health and activities. Several volcanoes are monitored through thermal surveillance based on a thermal camera (e.g., in Italy, Mt. Etna and Solfatara di Pozzuoli near Naples, and in USA, Hawaiian volcanoes); the information obtained by this monitoring instrument is included in the local hazard plan [17-21]. Because of the complexity of Earth Observed (EO) data, the use of medium-high spatial resolution spaceborne remote sensed data is less common.

The use of TIR satellite sensors is a consolidated technique [22] to identify volcanic activity. Different types of spatial resolution are adopted in literature: low (i.e., Meteosat Second Generation (MSG) or the Geostationary Environmental Satellite (GOES) with $4 \mathrm{~km}$ ground resolution) [23,24], medium (i.e., MODIS, AVHRR, Sentinel 3 with $1 \mathrm{~km}$ ground resolution) [25-27] and high (Advanced Spaceborne Thermal Emission and Reflection Radiometer (ASTER), and Landsat 8 (L8) with $100 \mathrm{~m}$ ground resolution) $[28,29]$. In the first case, the low spatial resolution of satellite sensors does not allow the detection of thermal anomalies in small areas of the order of a hundred meters, even if the high frequency of repeated revisiting time allows daily monitoring. In the second case, the medium spatial resolution of sensors provides TIR measurements daily and can be used for quantitative analysis including measurement of surface temperatures [30,31], effusion rates [30-33], and heat flux measurements [31,34,35], but also in this case, the spatial resolution does not allow the detection of small thermal anomalies. In the last case, the high spatial resolution sensors are the most useful for quantitative measurements and analysis [21,28] even if their low temporal resolution revisiting time of 16 days makes them ineffective for real-time monitoring due to the transient nature of many volcanic processes. 
In this work, ASTER and L8 time series are processed in order to identify thermal anomalies on the Island of Vulcano, which could potentially be related to changes in volcanic activity. In the literature, thermal anomalies are extracted from data with a spatial resolution of around $1 \mathrm{~km}$ (e.g., ATSR, MODIS, AVHRR) [36-38]. In this work, we use data with a spatial resolution of 90-100 m. We consider this resolution comparable with the extension of the crater area and therefore suitable to retrieve sufficient variation of the surface temperature sampled in detail, which seems comparable to the ground measurements performed along the volcanic area.

\section{Study Area}

Vulcano Island is an active volcanic system and represents the southernmost sector of the Aeolian archipelago located north of Sicily, along the southern margin of the Tyrrhenian Sea (Figure 1). The Aeolian archipelago includes seven islands and is an arc-shaped structure extending from the Island of Alicudi to Stromboli Island. Vulcano, Salina and Lipari Islands form a NNW-SSE elongated volcanic belt that cross-cuts the archipelago in its central sector along the Tindari-Letojanni strike-slip tectonic system [39-46].

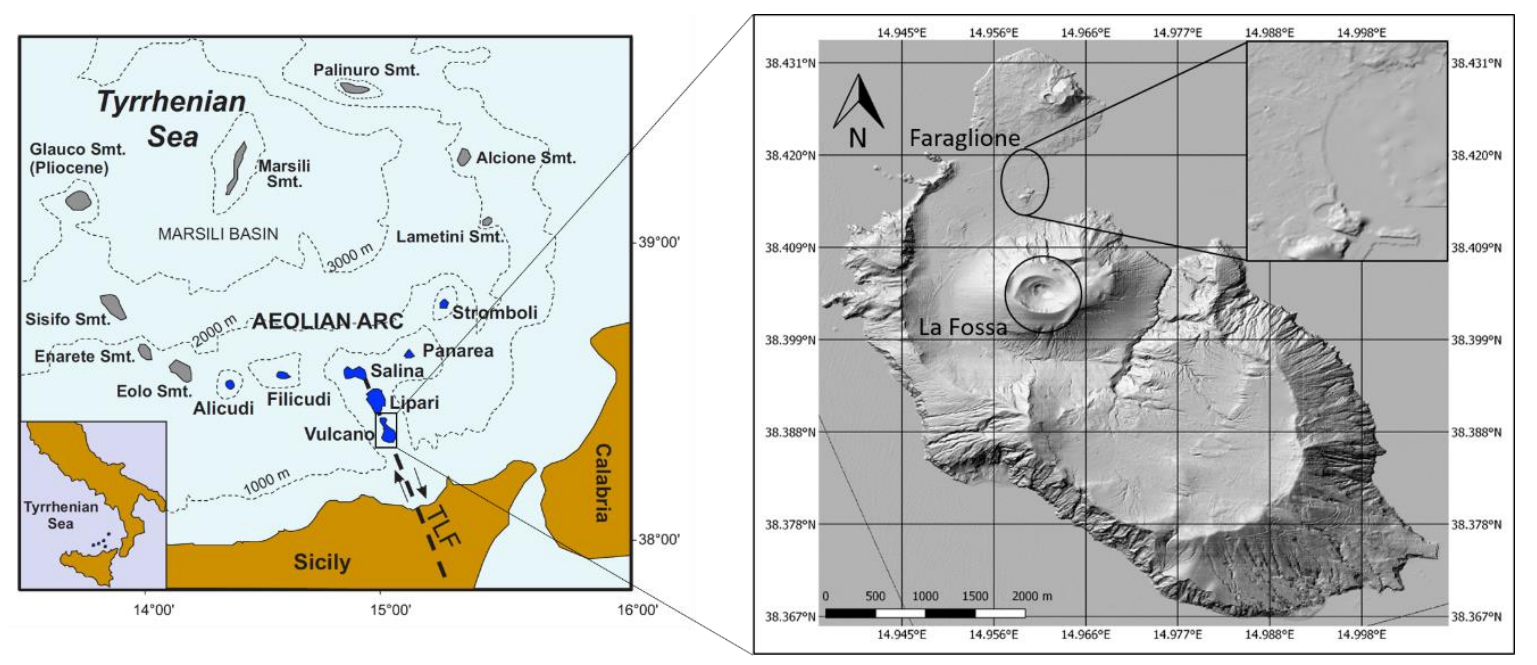

Figure 1. Location of the Island of Vulcano in the Aeolian archipelago, southern Tyrrhenian Sea and zoomed image of Vulcano based on a Lidar-derived DEM-shaded relief image [47].

Vulcano Island is actually in a quiescent stage characterized by intense and variable solphataric activity. The existing monitoring network has been set up over the last 30 years and new tools are still improving. Vulcano is composed of four main volcanic structures which become gradually younger moving toward the north and NW [48]: the south Vulcano center, the Lentia volcanic complex, Vulcanello and the La Fossa cone which is the most recent structure [49]. The eruptive history of Vulcano (from $127 \mathrm{ka}$ to present) has been well described by De Astis et al. [49] and its eruptive history can be summarized in eight episodes, between $127 \mathrm{ka}$ and historical times (AD 1888-1890) that show a long and complex eruptive history. The eruptive episodes are followed by variable periods of quiescence associated with volcano-tectonic collapse that gave origin to the calderas of Il Piano and La Fossa [49]. Each eruptive episode shows different styles ranging from lava flow to pyroclastic deposits [49,50] and also different chemical composition varying from shoshonitic to high-K calcalkaline and potassic series. The activity of La Fossa shows explosive phreatic and phreatomagmatic eruptions producing wet and dry pyroclastic surges, pumice fall deposits, and highly viscous lava flows [51].

Two caldera-type structures occur in the central sector of Vulcano and their formation can be related to events producing large volumes of ash-flow deposits and/or relatively moderate-sized explosive eruptions [41]. 
The structural pattern of Vulcano is dominated by the major NW-SE- to NNW-SSE-striking fault system [40-42,45,52], which is the superficial expression of the Tindari-Letojanni system [44,53].

The Piano and La Fossa calderas are the most important morpho-tectonic depressions of Vulcano Island and are bordered by NNW-SSE-, N-S- and NE-SW-trending lineaments, interpreted as a pull-apart basin with minor volcano-tectonic or volcano-related components [40,45].

Our study focuses on the area of the mud pool of "Fangaia", near Faraglione area, and La Fossa crater (Figures 1 and 2), which were formed starting from the latest eruptive episode $(<8 \mathrm{ka})$ [49].

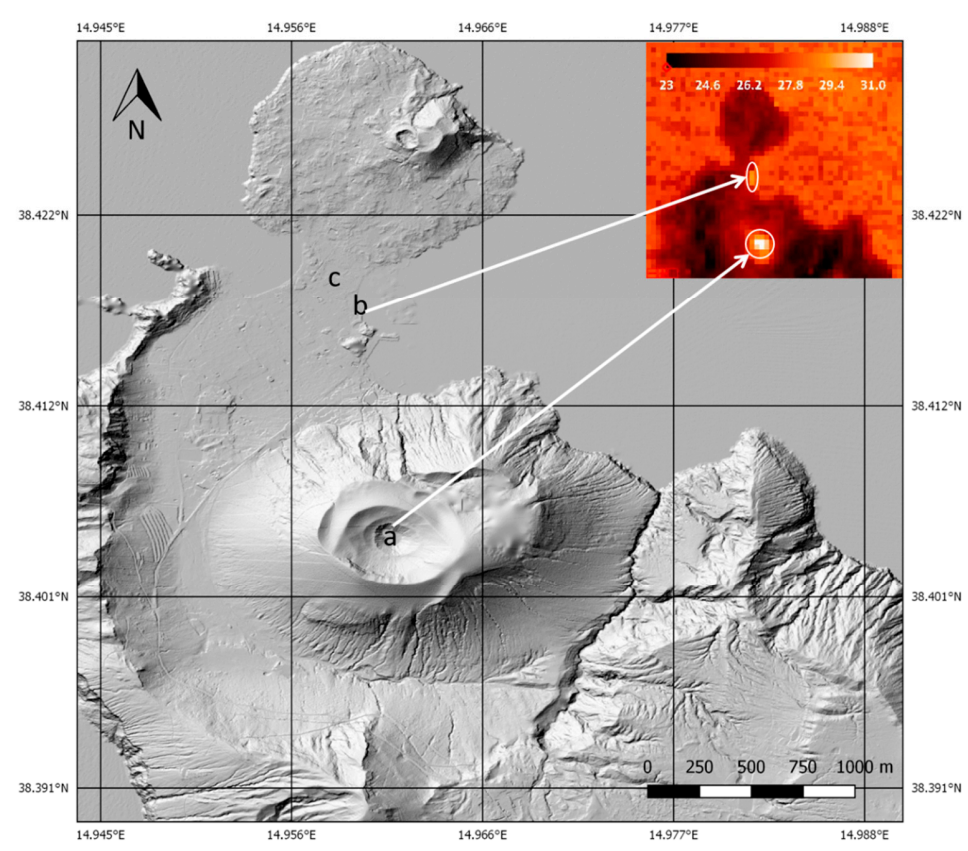

Figure 2. The two sites selected for the analysis: La Fossa crater (a), "Fangaia" mud pool (b) and Vulcano weather station (c). In the box the two areas viewed by L8 on 8 July 2017.

Faraglione is located near Levante harbour and belongs to the Vulcanello islet. It is geologically characterized by brecciated pyroclastic material, deeply altered by the strong hydrothermal release and locally hardened (Faraglione formation) with a leucite-bearing shoshonite composition [54], ascribed to the early Vulcanello activity [49].

La Fossa is a small stratovolcano that lies in the central part of the island; it reaches an elevation of $391 \mathrm{~m}$ a.s.l. and it has been active since $5.5 \mathrm{ka}$ [55]. La Fossa was formed by phreatomagmatic eruptions that generated dilute pyroclastic density currents [56] and references therein.

The thermal aquifers and the widespread $\mathrm{CO}_{2}$ soil degassing in these two areas testify to the actual volcanic activity [57-60].

Intense fumarolic degassing persists in La Fossa crater, and significant variations observed in the fumarole vents temperature at La Fossa crater were documented [13-15]. In 1926, fumarole temperatures reached more than $600{ }^{\circ} \mathrm{C}$ and the highest value, $670{ }^{\circ} \mathrm{C}$, was measured in 1993 [61]. Until March 1995, La Fossa temperatures were higher than $500^{\circ} \mathrm{C}$, while fumaroles located outside the crater vents ranged between $350^{\circ} \mathrm{C}$ and $500{ }^{\circ} \mathrm{C}$. After 1995, the temperature of fumaroles started to decrease while the surface of active vents increased, and many new vents opened at the edge of the active cone [12,62]. In particular, La Fossa crater is characterized by thermal anomalies that, during the seismic activity which occurred from 2004 to 2006 [63,64], were marked by strong increases of the temperature of the fumaroles and an increase of the size of the surface area covered by the fumarolic field.

In the summer of 2010, the fumaroles temperature reached its minimum value of $260^{\circ} \mathrm{C}$. 


\section{Materials and Methods}

\subsection{Satellite Data}

In this study, two satellite datasets were used: L8 with the on-board Thermal Infrared Sensor (TIRS), launched on February 2013 [29], and the ASTER sensor launched in December 1999 on the Terra satellite $[65,66]$. The TIR data time series were collected excluding cloudy scenes. The time series analyzed are radiance calibrated and geometrically corrected images (level 1T) of ASTER five TIR bands covering the period from 2000 to 2017 and level 1T L8 TIRS data covering the period from 2013 to 2017. In order to have the same spatial resolution for both data sets, the $100 \mathrm{~m}$ ground resolution TIR L8 data were re-sampled to correspond to the ASTER TIR spatial resolution of $90 \mathrm{~m}$ using the nearest neighbor resampling method.

In total, 208 nighttime images (170 images of ASTER data acquired from 2000 to 2017 and 38 images of L8 data acquired from 2013 to 2017) were used (Figure 3) to perform long-term surface thermal analysis which avoids the solar reflected radiance contribution, and allows comparison with the thermal camera and surface temperature collected by meteorological stations. Four daytime ASTER and L8 collected data sets were used to compare the results of a discontinuous ground campaign aimed to analyse the fumarole fields. In this second case, the solar insulation effect has not been separated in the retrieved surface temperature. ASTER and L8 data were atmospherically corrected. Then, the processor that produces the temperature map was applied.

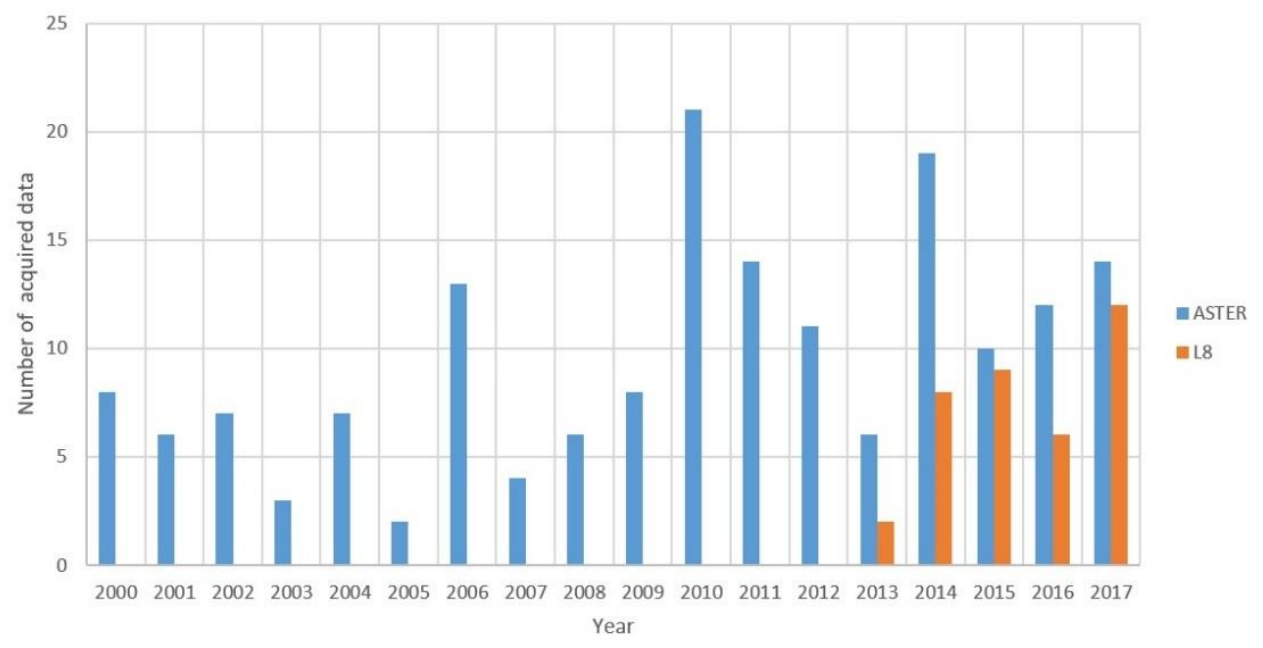

Figure 3. Histogram with the number of satellite acquisitions per year.

\subsubsection{Processing of L8 Data}

L8 carries two sensor payloads: the OLI (Operational Land Imager) and the TIRS (Thermal Infrared Sensor). In this work, band from 10.6 to $11.2 \mu \mathrm{m}\left(\mathrm{B}_{10}\right)$ acquired by TIRS sensor is used; $\mathrm{B}_{11}$ known calibration problems in the dual thermal bands of L8 [67,68] were taken into account and therefore are not considered.

Since the L8 TIRS data are delivered in quantized and calibrated scaled Digital Numbers (DN) representing all the multispectral image, the $\mathrm{B}_{10}$ data were automatically extracted and converted to Top Of Atmosphere (TOA) radiance by using the following equation:

$$
\mathrm{L}_{\mathrm{TOA}}=\mathrm{M}_{\mathrm{L}} \mathrm{Q}_{\mathrm{cal}}+\mathrm{A}_{\mathrm{L}}
$$

where:

$\mathrm{L}_{\mathrm{TOA}}$ is the Radiance at the top of the Atmosphere $\mathrm{W} \cdot \mathrm{m}^{-2} \cdot \mathrm{sr}^{-1} \cdot \mu \mathrm{m}^{-1}$; $\mathrm{M}_{\mathrm{L}}$ is the multiplicative rescaling factor $\left(3.342 \times 10^{-4}\right)$ for $\mathrm{L} 8 \mathrm{~B}_{10}$ metadata, from the MTL file furnished with the image data; 
$\mathrm{Q}_{\text {cal }}$ is the quantized and calibrated standard digital pixel number $(\mathrm{DN})$ value;

$A_{L}$ is the additive rescaling factor (0.1) for L8 $B_{10}$ metadata, from the MTL file.

Starting from the $\mathrm{B}_{10}$ TOA spectral radiance $\left(\mathrm{L}_{\mathrm{TOA}}\right)$, the influence of the atmosphere has been removed using the "CIRILLO" module [69] and the radiance emitted by the surface at specific wavelength $\left(\mathrm{L}_{\lambda}\right)$ has been obtained. CIRILLO is homemade software for the correction of spaceborne images acquired in the VIS-TIR spectral range. The atmospheric terms needed by CIRILLO are computed by the known radiative transfer models Modtran4.0 [70,71] and 6S [72]. Moreover, CIRILLO takes into account the illumination changes due to relief computing and corrects them starting from digital terrain models and solar position.

Using these data, the spectral radiance $\left(\mathrm{L}_{\lambda}, \mathrm{W} \cdot \mathrm{m}^{-2} \cdot \mathrm{sr}^{-1} \cdot \mu \mathrm{m}^{-1}\right)$ emitted by surface at temperature $\mathrm{T}(\mathrm{K})$ could be calculated by rearranging the following equation from [73]:

$$
\mathrm{L}_{\mathrm{TOA}}=\tau \varepsilon \mathrm{L}_{\lambda}+\mathrm{L}_{\mathrm{u}}+\tau(1-\varepsilon) \mathrm{L}_{\mathrm{d}}
$$

with:

$\mathrm{L}_{\mathrm{TOA}}$ the radiance received by $\mathrm{B}_{10}$ of the sensor with brightness temperature $\mathrm{T}_{10}$;

$\mathrm{L}_{\lambda}$ the radiance from the surface at $\mathrm{B}_{10}$;

$\mathrm{L}_{\mathrm{u}}$ the upwelling atmospheric radiance components (obtained using Modtran [70]);

$\mathrm{L}_{\mathrm{d}}$ the downwelling atmospheric radiance components (obtained using Modtran [70]);

$\varepsilon$ the surface emissivity for $B_{10}$ extracted by the ASTER 05 emissivity data [74];

$\tau$ the atmospheric transmittance for $B_{10}$ when the view zenith angle is $\theta$ (obtained using Modtran [70]). TIRS is treated as nadir viewing since the view angle is no more than $7.5^{\circ}$.

Atmospheric profiles in terms of pressure, temperature, geopotential height, relative humidity needed for obtaining the atmospheric components in (2) were downloaded from the University of Wyoming (WYO) website [75].

Since the focus of the investigation is the estimation of a surface temperature map, in order to invert equation (2), we have assumed the emissivity value provided by the ASTER05 reference map. The surface temperature has been obtained by applying the formula reported in [76]:

$$
\mathrm{T}=\mathrm{K}_{2} /\left(\ln \left(\mathrm{K}_{1} / \mathrm{L}_{\mathrm{TOA}}+1\right)\right)
$$

where

$\mathrm{T}$ is the surface temperature $\left({ }^{\circ} \mathrm{K}\right)$;

$\mathrm{L}_{\lambda}$ is the surface spectral radiance;

$\mathrm{K}_{1}$ is the Band-specific thermal conversion constant provided in the MTL file;

$\mathrm{K}_{2}$ is the Band-specific thermal conversion constant provided in the MTL file;

Once we obtained the temperature, the conversion to degrees Celsius was done in order to better compare with the measurements collected during the field campaigns.

\subsubsection{Processing of ASTER Data}

ASTER covers a wide spectral region with 14 bands, distributed along three sensors; the Thermal Infrared (TIR) sensor with 5 bands in the spectral range from 8.125 to $11.65 \mu \mathrm{m}$ at spatial resolution of $90 \mathrm{~m}$ has been used in this work.

The standard TIR ASTER L1T products were used to estimate the surface temperature from the ASTER data using the Temperature Emissivity Separation (TES) algorithm [77]. The atmospheric correction was performed using "CIRILLO" atmospheric correction tools [69] as described in the previous section. 


\subsection{Ground Measurements}

\subsubsection{Direct Measurements from Continuous Monitoring Stations}

Vulcano is constantly monitored by a ground network of instruments for continuous acquisition of fumaroles present on top of the crater. Sensors position equipped with thermometers are located on the main active fumaroles, to track changes from the high temperature of fumaroles (HTF), shown in Figure 4 (modified from [13]).

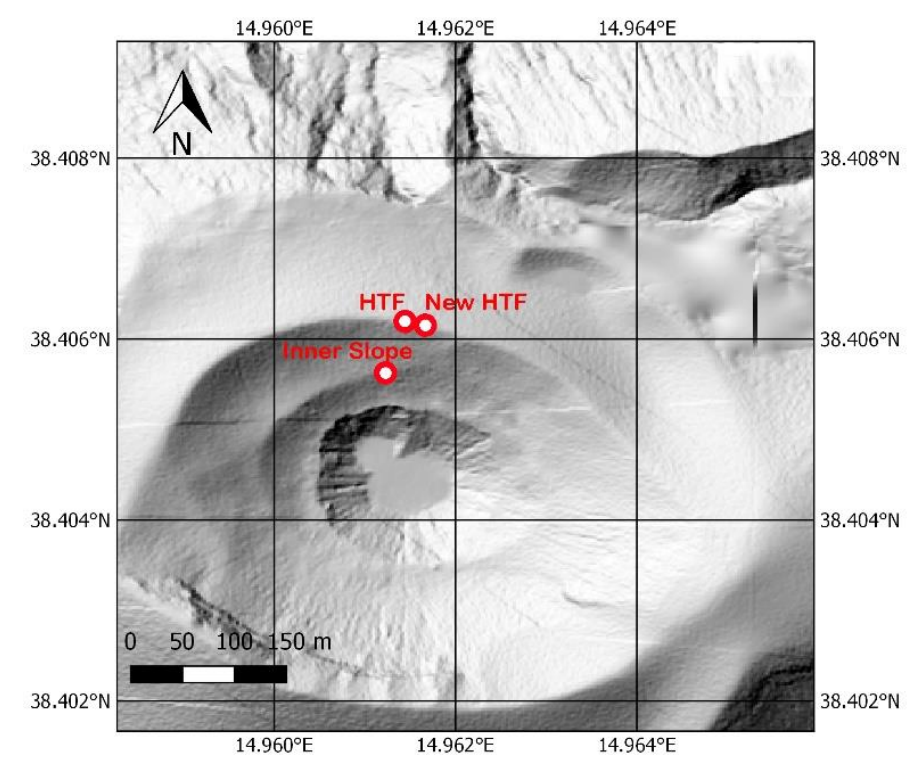

Figure 4. Location on the top of La Fossa Cone of the sensors for the thermal monitoring included in the INGV network (on a Lidar-derived DEM-shaded relief image [47]). The interval of acquisition is one hour.

The monitoring network components are thermal probes, inserted within the fumarole vents at a depth of $50 \mathrm{~cm}$, consisting of thermocouples (K type). The buried part of the thermo-couple wire is protected by a cylindrical case, made by stainless steel, while a head made of teflon protects a part of the electronic components of the system from the direct exposure to acidic fluids [13-15].

Many other temperature measurements were occasionally carried out on the La Fossa crater with a portable low-cost radiometer assembled into the Pyrogips system [78,79]. This instrument supplies the advantage of in situ methods (i.e., accuracy of direct measurement by a thermocouple) producing a detailed grid of surface temperatures that can be very useful for establishing a network of sampling points or installing a new site for geochemical monitoring. The string of data returns the GPS position, surface temperature (derived from the pyrometer and thermocouple), ambient temperature, barometric pressure and air moisture. The surface temperature acquired during four field campaigns (2012, two in 2014 and 2017) was used to compare them with the temperatures estimated by satellite data acquired, considering dates and time as close as possible to the ground survey. In Table 1 the dates for each campaign and available satellite data are reported. Since the surveys were conducted during the morning, daytime satellite acquisitions (about 09:30 UTC) were processed by using the same methodology described in Section 2.1 and its subsections. 
Table 1. Ground and Satellite data.

\begin{tabular}{cccc}
\hline \multicolumn{2}{c}{ Ground Survey } & \multicolumn{2}{c}{ Satellite Data } \\
\hline Date & Site & ASTER & L8 \\
\hline $12 / 06 / 2012$ & La Fossa Crater & $16 / 06 / 2012$ & $-\overline{1}$ \\
$15 / 09 / 2014$ & La Fossa Crater & $19 / 09 / 2014$ & $11 / 09 / 2014$ \\
$26 / 04 / 2017$ & La Fossa Crater & $\overline{28}$ & $284 / 2017$ \\
$15 / 09 / 2014$ & Fangaia & $19 / 09 / 2014$ & $11 / 09 / 2014$ \\
\hline
\end{tabular}

However, the cost to benefit ratio of the in situ measurements cannot be suggested for the geochemical surveillance of Vulcano since it is less convenient in comparison to the growing technical facilities offered by thermal remote sensing both proximal (by drone or by airplane) and by satellite [7].

\subsubsection{Proximal Thermocamera Imaging with Hand-Held IR Camera}

The infrared thermography is based on radiation heat transfer which is an energy transport mechanism that occurs under the form of electromagnetic waves. During this transport, radiant energy may partially be absorbed and reflected by a body. Consequently, the intensity of radiation received at the optical sensors depends on several parameters such as emissivity, viewing angle, atmospheric effects instrumental noise and, particularly for volcanic targets, it depends on the thermal heterogeneity of the target [18,62,80-85].

Hand-held IR camera technology has considerably improved over the last decade, resulting in a proliferation of commercially available instruments, which allow volcanic observatories to achieve indirect thermal monitoring.

The camera features are reported in Table 2.

Table 2. Hand-held IR camera features.

\begin{tabular}{cc}
\hline \multicolumn{2}{c}{ IR Camera Features } \\
\hline Temperature range & $20^{\circ} \mathrm{C}$ to $650^{\circ} \mathrm{C}$ \\
Field of view /min focus distance & $25^{\circ} \times 19^{\circ} / 9.8^{\prime \prime}(0.25 \mathrm{~m})$ \\
detector type-Focal plane array & $640 \times 480$ pixels $(\mathrm{FPA})$ uncooled microbolometer \\
Spectral range & 7.5 to $14 \mu \mathrm{m}$ \\
Lens & $25^{\circ}$ \\
Accuracy & $\pm 2{ }^{\circ} \mathrm{C}$ \\
\hline
\end{tabular}

The camera was calibrated before and after the survey held on 16 July 2014, with a variable temperature target. This initial pre-processing of the TIR imagery required the conversion of at-sensor-radiance values to surface temperature using a first-order correction for atmospheric absorption, surface emissivity and ambient temperature effects using ResearchIR Software. This correction includes the distance from the target to the camera, the atmosphere temperature and the humidity content, all measured in situ. An emissivity value of 0.95 was used for the first-order correction that is an appropriate value for this kind of volcanic rock, i.e., basalt with a smooth surface ranged from 0.971 to 0.975 [84].

Although the cameras are intrinsically temperature-calibrated, numerous extrinsic field conditions can compromise the correct temperature measurements [84-87]. The IR camera usually measures an apparent temperature for several reasons lower than the actual surface temperature. If there is much condensed water in the plume, the target surface may be entirely or partially blocked by fume, attenuating the radiant signal of the surface significantly [85]. The pixel footprint size also plays a part in the temperature accuracy—and effective sensitivity—of the cameras [84] because an individual pixel temperature is a composite of all the temperatures within the pixel footprint. If the hot target is small and the majority of the pixel area is cooler, this "mixed pixel" issue results in the pixel-integrated temperature being significantly lower than that of the hot target. 


\subsubsection{Meteorological Data}

Data from the weather stations located near the study areas were compared to the different time series of ground temperatures to verify if the trends of ground temperatures observed and both direct and indirect measurements are related to external changes (Section 2.2.1).

Prior to interpreting the observed temperature ground variations, due to the complexity of volcanic and hydrothermal system, it is useful to discriminate the different influences of the external components as they affect primarily the air temperature, but they also influence the ground temperatures.

In previous studies, the rainfall, barometric pressures, and normal air temperatures have been obtained by the Servizio Informativo Agrometeorologico Siciliano (SIAS, Regione Siciliana), that is the regional network of weather stations $[14,15]$. The two weather stations in Figure 5 were considered, because they are located both at a safe distance from the hydrothermal influence and the local volcanic activity, while their locations reflect the normal weather conditions of the region.

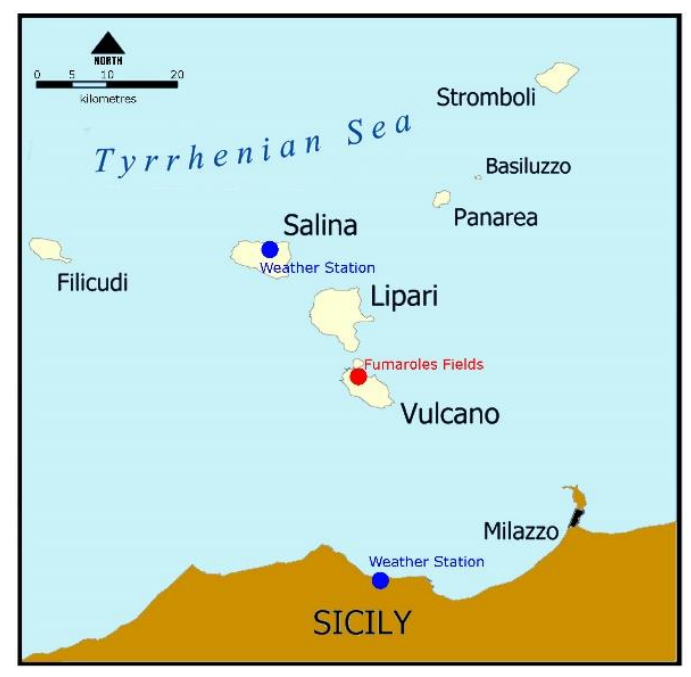

Figure 5. Weather station and fumaroles fields.

The historical weather data were acquired from a weather station near Vulcano harbor, under public access provided by the Oplao web site [88]. The web site offers a data archive of weather information from July 2008 until today. These temperatures were used to compare the trend of surface temperature estimated by satellite data with the local climate, as validation measurements and for representative of the soil-atmosphere interface temperature. When the satellite data were available during the 2008-2017 period, the temperature, reported at 21:00 UTC was compared daily with the results of the satellite-processed data, by a paired dataset.

This comparison is aimed to verify if the background temperature trends, derived by satellite image processing, and validation measurements provided by the weather station near Vulcano harbor, have similar behavior, fostering the capability to extend local measurements to a wider area.

\subsection{Airborne Data}

In order to introduce an intermediate observational scale and instrumental resolution between the direct measurements and satellite data, multispectral airborne data were acquired and elaborated. The measurement campaign took place in the period 10-12 September 2010 [89]. This campaign was characterized by measurements made by the Airborne Thematic Mapper (ATM) multispectral plane sensor, and contemporaneous on-site validation measurements made by ground instrumentation on both marine and terrestrial surfaces. The airborne remote sensing mission was carried out by the crew of a Coast Guard aircraft, an ATR 42 aircraft, with a SENSYTECH AADS 1268 ATM-E scanning system installed on board. This sensor consists of a passive scanner for aerial remote sensing that 
records the reflected and emitted terrestrial radiation, divided into 11 spectral bands ranging from Visible to Thermal Infrared. The flight on Vulcano Island was carried out according the acquisition characteristics reported in Table 3.

Table 3. Main characteristics of the predawn ATM flight.

\begin{tabular}{cc}
\hline \multicolumn{2}{c}{ ATM Airborne Characteristics } \\
\hline Data and time & $12 / 09 / 1003: 07 \mathrm{GMT}$ \\
Flight height & $4000 \mathrm{ft}$ \\
Plane velocity & $161 \mathrm{nodes}$ \\
IFOV & $2.5 \mathrm{mrad}$ \\
FOV & $85.92^{\circ}$ \\
Scan line & $712 \mathrm{pixels}$ \\
Scan Speed & $25 \mathrm{scan} / \mathrm{s}$ \\
Ground pixel & $\sim 3 \mathrm{~m}$ \\
\hline
\end{tabular}

\subsection{Statistical Indices}

The analysis of the mean of surface temperature retrieved by satellite data in an area of about 0,13 Sq.km for the La Fossa crater and about 0.1 Sq.km near the "Fangaia" mud pool, and the temperature measured by the meteorological station located in the Vulcano harbor offers a very interesting cross comparison and allows us to validate the methodology used for the satellite data surface temperature. In order to emphasize the agreement among the analysed datasets, we choose to apply the following statistical indices: Pearson correlation (Equation (4)), the Normalized Standard Error (NSE, Equation (5)) and the Normalized Bias (NB, Equation (6)). These indices give quantitative measurements of the relationship between the two measurements and demonstrate a high degree of correlation.

$$
\begin{gathered}
\text { Pearson correlation }=\frac{\sum_{i=1}^{N}\left(M_{i}-\bar{M}\right)\left(S_{i}-\bar{S}\right)}{\sqrt{\sum_{i=1}^{N}\left(M_{i}-\bar{M}\right)^{2}\left(S_{i}-\bar{S}\right)^{2}}}, \\
N S E=\frac{\sqrt{\left(\sum_{i=1}^{N}\left(M_{i}-S_{i}\right)^{2}\right) / N}}{\left(\sum_{i=1}^{N} M_{i}\right) / N}, \\
N B=\frac{\sum_{i=1}^{N}\left(S_{i}-M_{i}\right)}{\sum_{i=1}^{N} M_{i}},
\end{gathered}
$$

where $\mathrm{N}$ is the total number of processed data points, $\mathrm{Si}$ and $\mathrm{Mi}$ are the satellite surface temperature and meteorological station temperature of the i-th measurements, and $\bar{S}$ and $\bar{M}$ are the average of the mean of Si and Mi, respectively.

\section{Results}

\subsection{Surface Temperature Retrieved by Satellite Data and Weather Station Time Series}

Here we focus on the time series obtained by analysing 170 nighttime images of ASTER data acquired from 2000 to 2017 and 38 nighttime images of L8 data acquired from 2013 to 2017. The meteorological station time series were collected considering the same day and time of satellite acquisition in order to compare the information. Two areas of Vulcano Island were considered: $\mathrm{La}$ Fossa crater and the mud pool "Fangaia" areas. These sites have been selected because they have an apparent temperature higher than the surrounding area. In Figures 6 and 7, the scatter plots of the surface temperature retrieved by the satellite and those registered by the meteo station for the two test areas and the three correlation indices are displayed. 

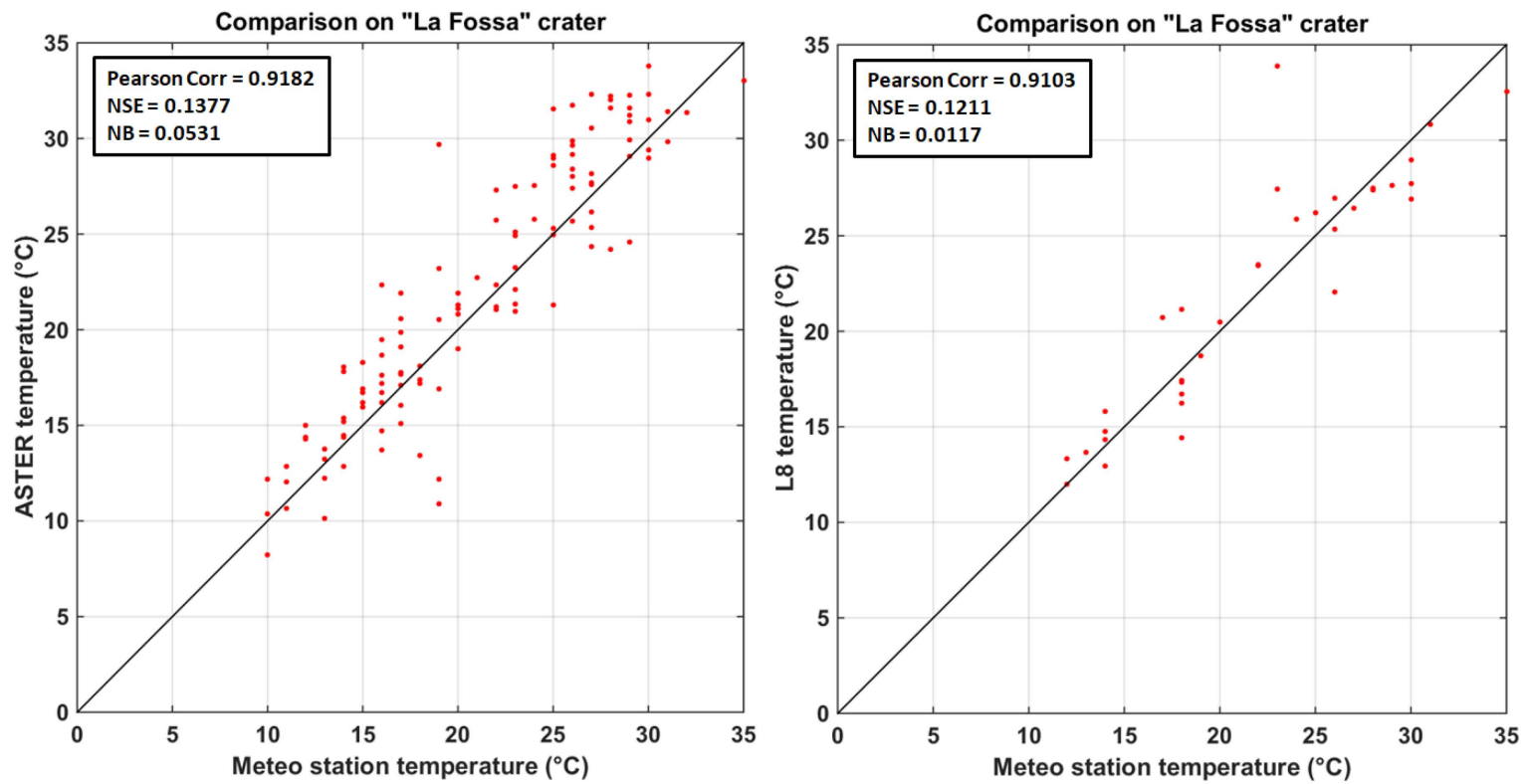

Figure 6. Scatter plots of surface temperature retrieved by ASTER (left) and L8 (right) data and temperature measured by the meteo station on La Fossa crater.
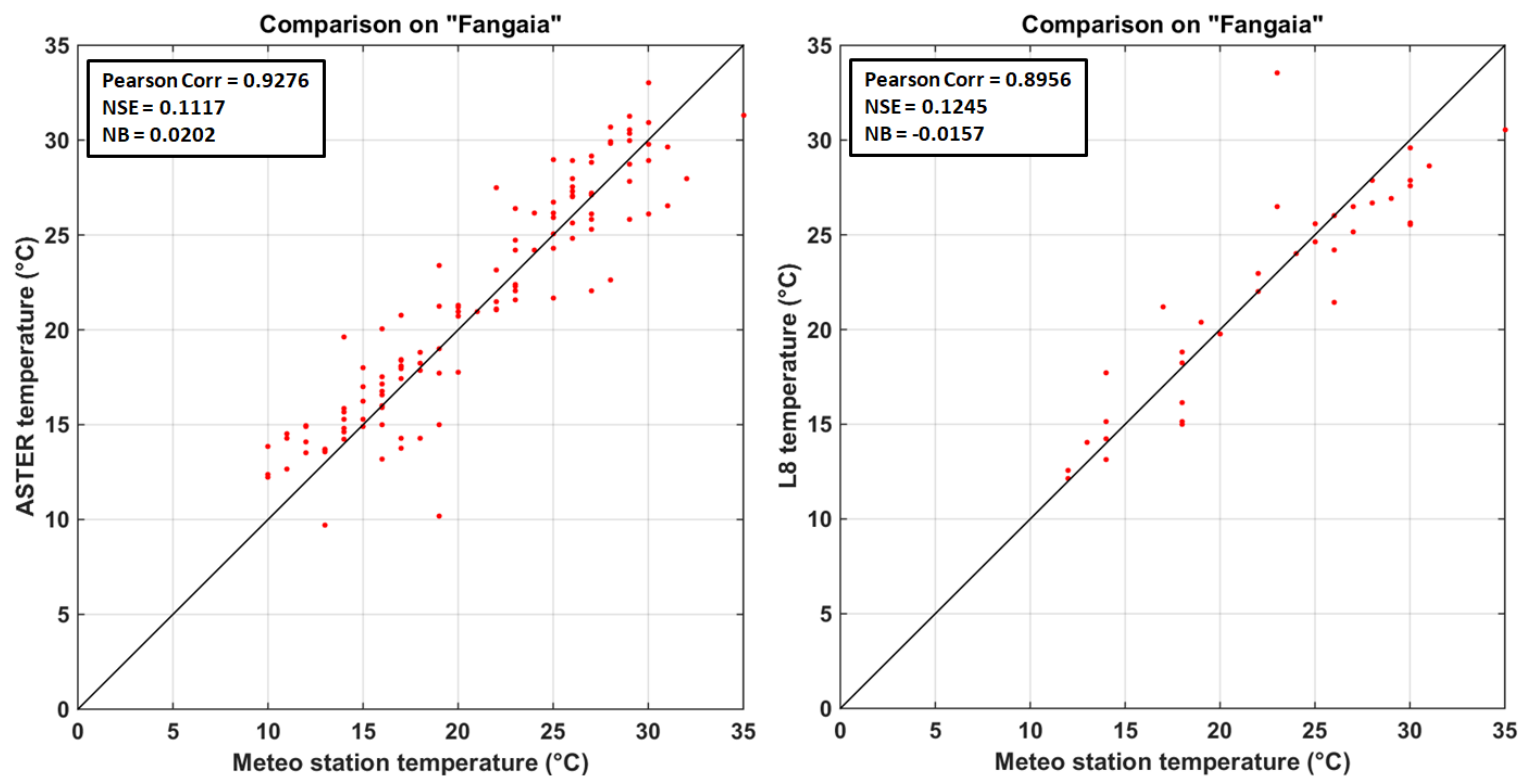

Figure 7. Scatter plots of surface temperature retrieved by ASTER (left) and L8 (right) data and temperature measured by the meteo station in "Fangaia" mud pool.

Concerning the ASTER time series, we can reasonably state that the strong agreement between the meteorological observation and satellite data starting from 2008 can validate the methodology for the evaluation of temperature by using satellites. Moreover, even if no meteorological data are available before July 2008, the agreement showed in Figures 6 and 7 allows us to extend the validity of the ASTER time series for the period ranging from 2000 to 2008. As L8 acquisition started in 2013, it is not possible to extend this analysis backward.

During a field campaign on 3 September 2015, surface temperature was measured on the top of the La Fossa crater by using a thermometer installed in a multisensor instrument. The measured value [90] is coherent with the Oplao web site value and with the temperature estimated by L8 data acquired only two days later (Table 4). This comparison (even if related to only one day) can be considered as further confirmation of the methodology used to estimate the temperature from satellites. 
Table 4. Comparison of temperature derived from the web site, field campaign and L8 data.

\begin{tabular}{ccccc}
\hline Point Lat/Lon & Time UTC & $\begin{array}{c}\text { Oplao Web Site } \\
\text { 5/9/2015 }\end{array}$ & $\begin{array}{c}\text { Field Campaign } \\
\text { 3/9/2015 }\end{array}$ & L8 5/9/2015 \\
\hline $38.40612^{\circ}, 14.96066$ & $5: 43 \mathrm{AM}$ & $29^{\circ} \mathrm{C}$ & $28.4^{\circ}$ & 29.69 \\
\hline
\end{tabular}

\subsection{Ground Field Campaigns}

\subsubsection{Time Series from Continuous Monitoring Stations}

The temperature time series, plotted in Figure 8, are the result of the long-term monitoring of 4 fumarole vents, which in the last 30 years have shown temperature variations ranging on the whole, from $670{ }^{\circ} \mathrm{C}$ to $120^{\circ} \mathrm{C}$. Since September 1991, 24 temperatures a day have been recorded and validated for the sites selected for volcanic surveillance. The output temperatures of the main fumaroles located on the top of La Fossa cone have not been stationary, a few changes in trends and many impulsive variations affected all the monitored sites [13].

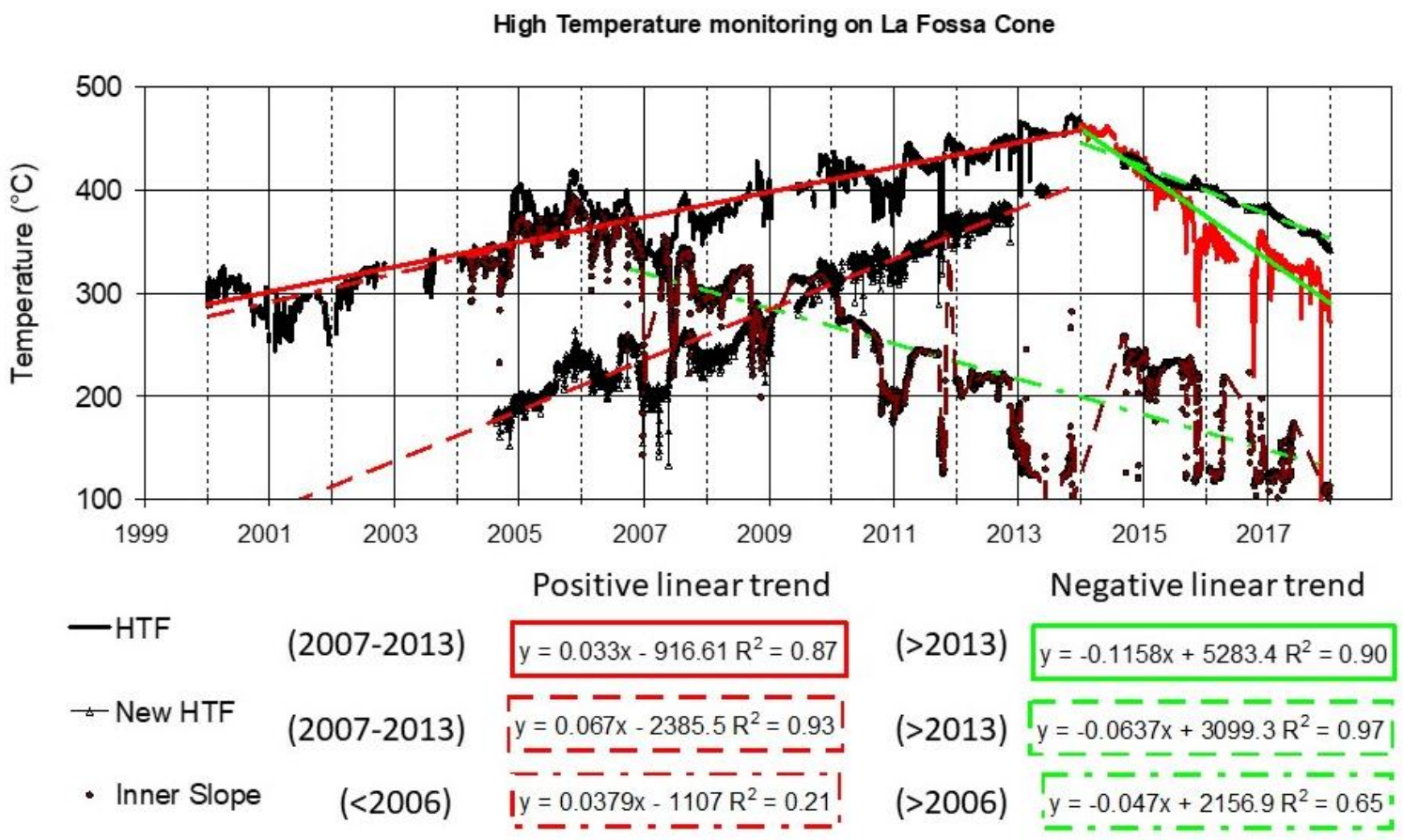

Figure 8. Time series of temperature selected from the continuous monitoring network of INGV.

The linear trends of emission temperatures recorded by the monitoring network are highlighted in Figure 8, and their best-fitting equations have been reported in the legend. The monitored fumaroles located on the rim zone (HTF and New HTF in Figure 4) have shown two positive trends for more than ten years, until the end of 2013 (Figure 8). At least from the year 2004, and 4 years later, the fumaroles located on the inner slope have shown the same time variations as the fumarole on the rim zone (compare the time variations of HTF and Inner Slope in Figure 8). Then, the trend of temperatures on the inner slope (Inner Slope in Figure 4) dramatically diverged from the trend of the rim zone, during the year 2007. The beginning of 2007 was characterized by strong decreases recorded in all the monitored fumaroles but, while the upper rim recovered the positive trending variations of temperature, the inner slope continued to show a decreasing trend. Afterwards, until the end of 2017, the main features shown by the fumarole temperature of the inner slope have been the strongest perturbations of external origin, due to the seasonal changes of weather conditions.

On the active cone of La Fossa [91], the experimental acquisition of ground temperatures was performed at 4 different sites during three years, from 2004 to 2007. The measurements of ground 
temperature, made by contact probes, showed that three of these sites were characterized by anomalous profiles of temperature, suggesting a heating source located below. These stations highlight a process of steam heating within the ground and a thermal source, and they allow us to evaluate the heat flux from the soil. Under dry conditions, that is in the absence of steam or water within the monitored profile, the conductive heat flux is the only form of heat transfer, thus the temperature of the ground is the only detectable variable in order to evaluate the heat flux coming from the soil heated by a steam source located at the bottom of the monitoring profile.

\subsubsection{Proximal Yhermocamera Imaging with a Hand-Held IR Camera}

The geothermal flux and volcanic gas activity generate positive anomalies mainly at the surface, located along the rim and in the inner flank of La Fossa cone. A simplified, steady-state thermal budget model was used to map the thermal anomalies of this sector of Vulcano. The ground measurements show well-localized and thermally active zones. The thermal infrared images present a visualization of the heat flux associated with these structures.

Generally, two physical characteristics of the exposed surfaces are the main causes of the space variability of temperatures: the thermal capacity of the exposed surfaces and the shallow permeability of the ground.

The surface of the cone of La Fossa on the top is not homogeneous. It is covered by later La Fossa Tuffs, pyroclastic breccias, including large bombs. Sand tuffs and breccias show interrelation of ashes, some with accretionary lapilli, although subordinate, authigenic-juvenile material erupted in the form of thin pumice layers and some larger scoriae bombs. Moreover there is a diffuse interbedding of argillitic alteration residual and fumaroles deposits. The enlargement of the exhaling area and/or an increase of thermal anomaly surrounding the main fumarole vents (due to steam heating from the bottom source) can highlight significant increases of thermal release even if the maximum temperature of fumarole fluids falls. Responding to thermodynamic basic principles, the exchange of energy drives each component towards the thermal equilibrium.

During the survey on 16 July 2014 , soil temperatures ranged from $20^{\circ} \mathrm{C}$ to $114{ }^{\circ} \mathrm{C}$ on the fumarole field at a distance of 300 at the bottom to $400 \mathrm{~m}$ on the top of the rim. Figure 9 shows the thermographic map of the main diffusive and thermal manifestations after optical and atmospheric corrections required; a mixed area with diffuse heat flux (yellow) and an area with high temperature vents (red) are widespread in a region with low temperature (blue).

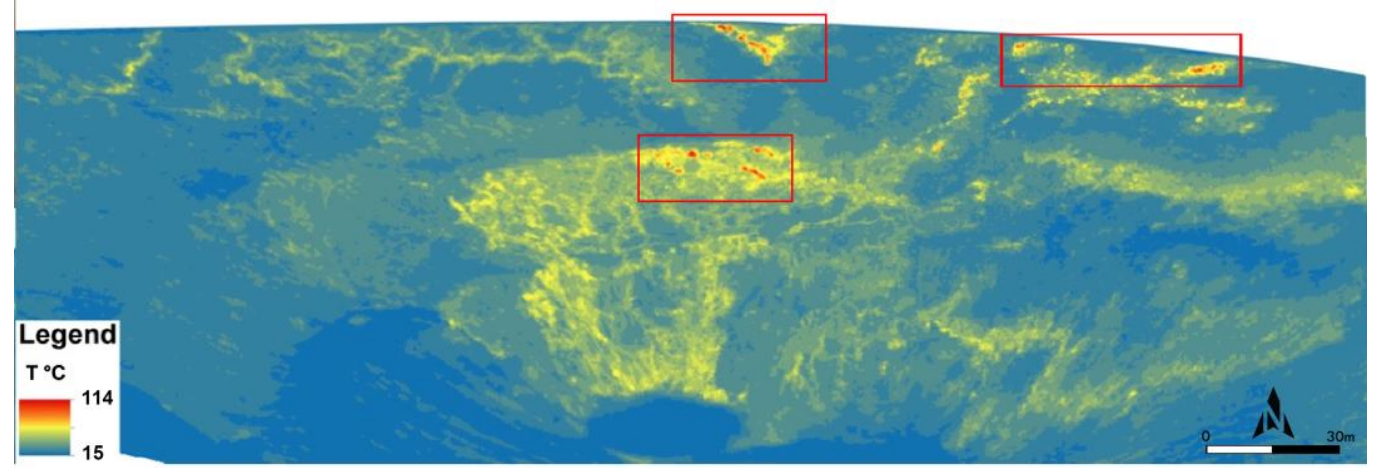

Figure 9. Thermographic map of the La Fossa crater rim acquired on16/07/2014 with a hand-held IR camera. The red boxes mark the craters showing high thermal anomalies.

The statistical analysis applied to sequences of the thermal images analysed aims to define the extension of thermal anomalies, contributing to the evaluation of surface flux. The Normal quantile-quantile plot (QQ plot, Figure 10) is a graphical tool to verify if a set of data came from some theoretical distribution, such as a normal or exponential one. The data values are ordered and the cumulative distribution values are calculated as $(i-0.5) / n$ for the $i$-th ordered value out of $n$ total 
values. The scatterplot is created by plotting the real set of quantiles against the normal distributed population of the same quantiles; a line that is roughly straight corresponds to a normal distribution of the real dataset. Any diversion from the straight line indicates a diversion of the dataset from the normal distribution. The probability plots reveal different populations of data. According to these populations the space variability observed on the surface temperatures has been inferred from the main components of the heat transport (radiative, convective conductive) which participated in the heat exchange processes according to the different rate of flux reaching the ground surface.

The temperature distribution on a probability plot, as shown in Figure 10, was the visual method used for discriminating the different groups, and also for choosing the scale of values for the temperature thematic maps. We interpreted the lowest class of ground temperature $\left(<20^{\circ} \mathrm{C}\right)$ as falling in the water saturated layer; the second class of values (included in the range from 20 to $27^{\circ} \mathrm{C}$ ) was interpreted as the surface condition dominated by conductive heat transfer, absence of liquid water and very low steam content; the third class (temperatures in the range from 28 to $48^{\circ} \mathrm{C}$ ) was for the steam heated soil; finally, the hottest class of values included the low temperature fumaroles $(\mathrm{T}>48)$, where the convective transfer dominates.

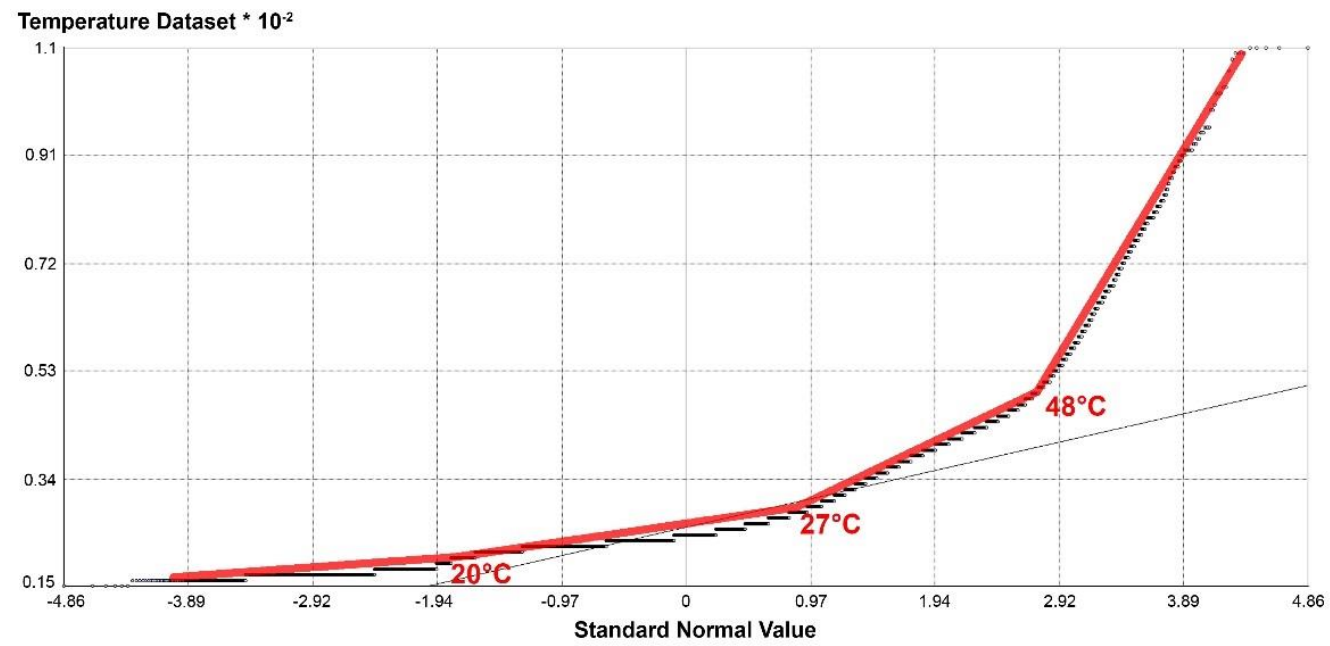

Figure 10. qq-plot of the infrared temperature measurements (La Fossa crater rim). The red line identifies the thermal quantile groups of dataset and the range temperature; the black line is the reference line to assess the Normal Gaussian distribution assumption).

\subsection{Airborne Campaign}

The airborne survey carrying the multi-spectral infrared and visible imaging spectrometer (ATM) was carried out with the primary objective of obtaining high-spatial-resolution thermal images of the Vulcano Island. The predawn airborne thermal data of channel $10.5 \mu \mathrm{m}$ were examined in order to retrieve sea and land surface temperatures, with particular attention to fumarole areas emitting at higher temperatures (about $50^{\circ} \mathrm{C}$ ). Thermal data were corrected for atmospheric and reflection effects by using equation (2). Parameters of the equation were obtained using the Modtran model atmosphere [70,92]. Using a sea-land mask we successively identify the thermal anomalies within the area (Figure 11). The striping effect showed in Figure 11 is an artifact due to the generation of the image and it does not influence the quality and results of the applied procedure. Sea temperature retrieved from airborne data was compared with data obtained from contemporaneous ground field measurements using a portable thermo radiometer and handheld thermal camera. 


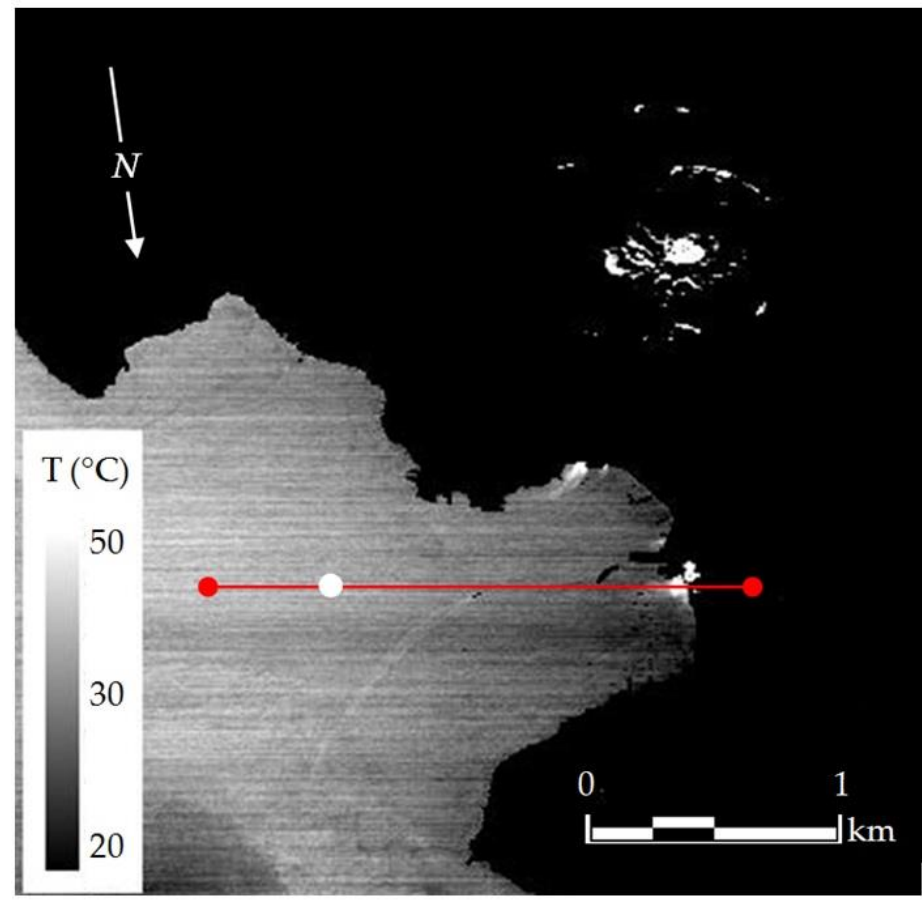

Figure 11. Surface temperature retrieved by ATM from the 12 September 2010 predawn flight. Higher temperatures relate to fumaroles distributed within the La Fossa crater and along the coast of the Volcano bay. The red line corresponds to the temperature profile of Figure 12 and the white dot to the measurement location of Figure 13.

Gas emissions are observed both in the crater and in the beach area (Fumarole beach) at the northern foot of the La Fossa crater; vents also occur at different sites off the island. The presence of submarine gaseous emissions along the coast of "Fangaia" area is evidenced.

In Figure 12 the temperature profile derived from the map thermal distribution of Figure 11 is shown.

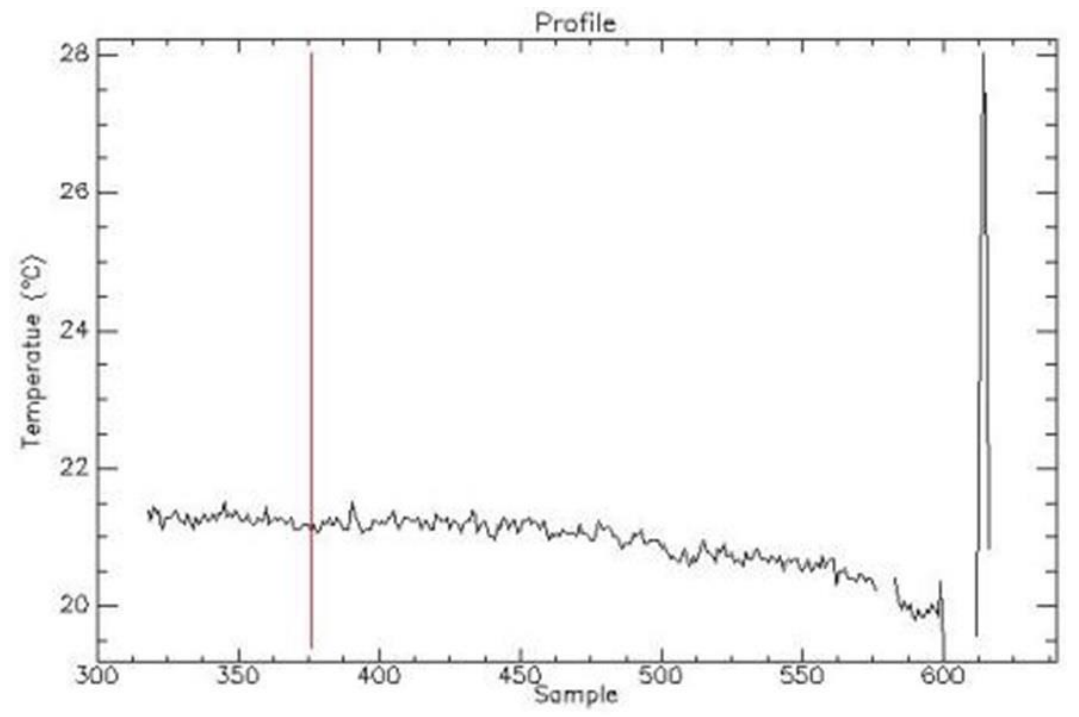

Figure 12. Sea water temperature profile along the red line shown in Figure 11. The red line intersects the temperature value estimated at that location of Figure 13. 
The water temperature profile shows a regular decrease in temperature starting from the open sea to the coast. This is due to the slow night sea cooling down, since the water has higher specific heat capacity than land. Near the coast, temperatures increase suddenly and sharply due to the presence of submarine gas emissions. The average temperature rises from $20^{\circ} \mathrm{C}$ in the sea to about $28^{\circ} \mathrm{C}$ in the land.

In the case of the submarine fumarole area, it was possible to compare temperatures derived from remote sensing data and contemporaneous field measurements. Figure 13 shows the water surface temperature measured from thermal camera. A temperature of $21.9^{\circ} \mathrm{C}$ was measured which is in good agreement with the ATM-derived temperature of $21.6{ }^{\circ} \mathrm{C}$.

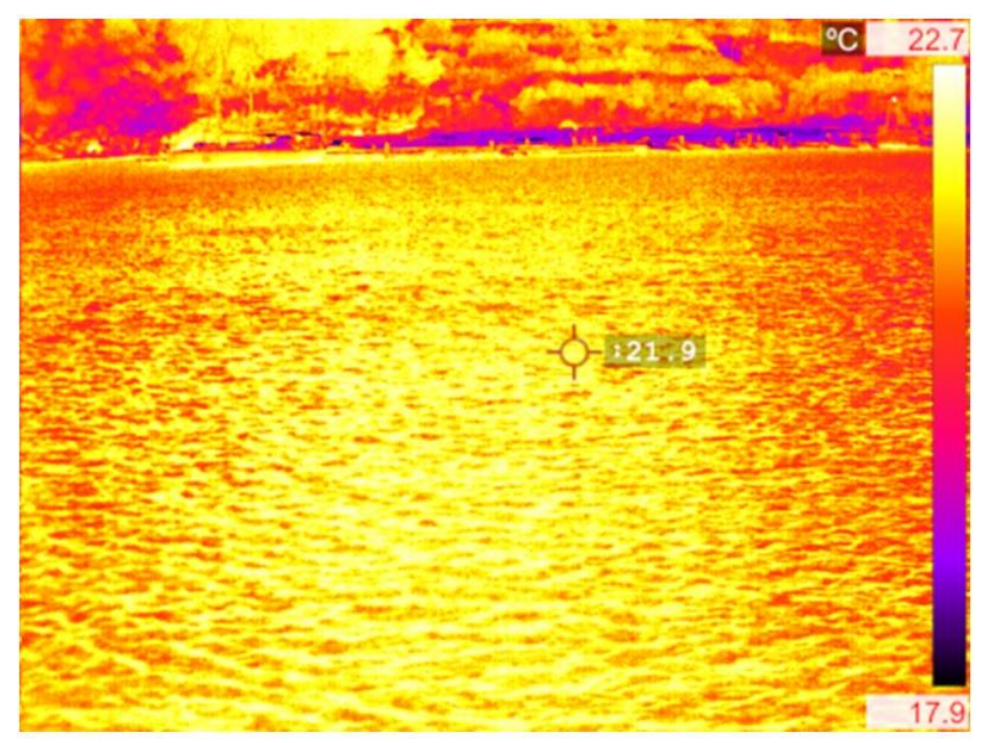

Figure 13. Sea water measured from the thermo camera.

\section{Discussion}

In the next sections the comparison between multiscale and multitemporal will be described.

\subsection{Satellite Data Compared with Ground Data}

We have generated subsets of collected ground temperature considering those included in a pixel of $90 \times 90 \mathrm{~m}$ (corresponding to L8 and ASTER pixel size). For each of these subsets the average ground temperature has been calculated and compared with surface temperature estimated by satellites (Tables 5-7). Taking into account the satellite spatial resolution, 15 satellite pixels drape the ground distribution of collected points.

In Figures 14-17, the draping of the 15 identified satellite pixels is overlapped on the path followed during the field campaign reported in Table 1. 


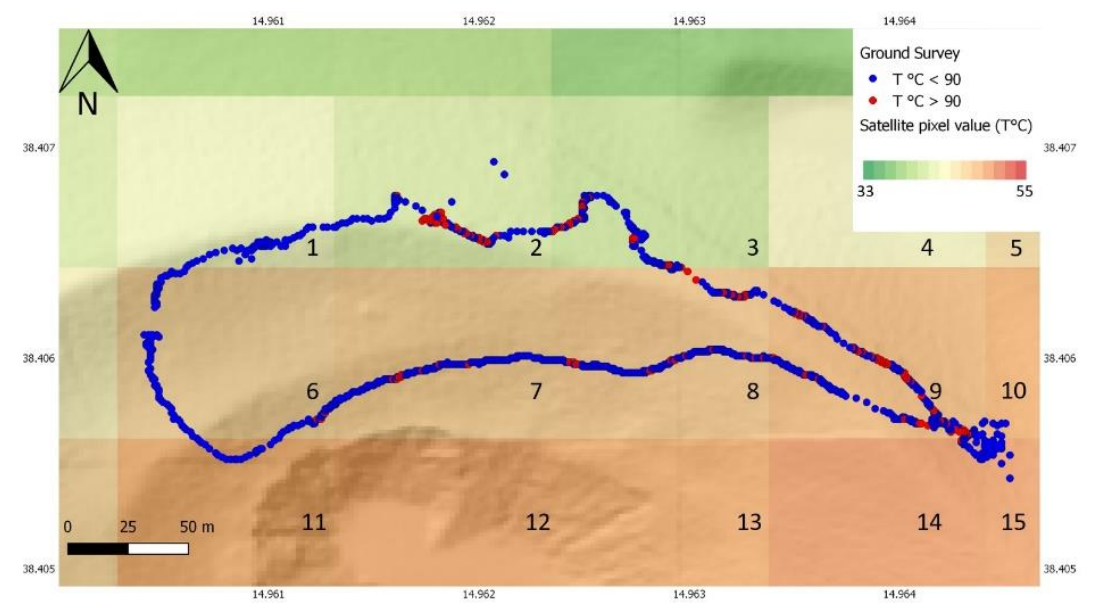

Figure 14. Ground survey point distribution inside the satellite images pixel boundary. Data of survey 12/06/2012 and ASTER acquisition on 16/06/2012.

Table 5. Comparison between ground measurements and satellite estimation temperatures on La Fossa crater (Field campaign 12/06/2012 and ASTER data 16/06/2012).

\begin{tabular}{ccc}
\hline $\mathbf{N}^{\circ}$ Pixel & Ground $\mathbf{T}\left({ }^{\circ} \mathbf{C}\right)$ & ASTER T $\left({ }^{\circ} \mathbf{C}\right)$ \\
\hline 1 & 23.94 & $41.10 \pm 4.87$ \\
2 & 101.32 & $44.30 \pm 4.51$ \\
3 & 69.08 & $46.50 \pm 4.30$ \\
4 & - & - \\
5 & - & - \\
6 & 48.49 & $43.00 \pm 4.65$ \\
7 & 60.93 & $46.40 \pm 4.31$ \\
8 & 63.91 & $48.90 \pm 4.09$ \\
9 & 74.10 & $49.10 \pm 4.07$ \\
10 & 31.80 & $49.10 \pm 4.07$ \\
11 & 43.24 & $46.40 \pm 4.31$ \\
12 & & \\
13 & & \\
14 & 60.76 & $52.40 \pm 3.82$ \\
15 & 35.21 & $49.10 \pm 4.07$ \\
\hline
\end{tabular}

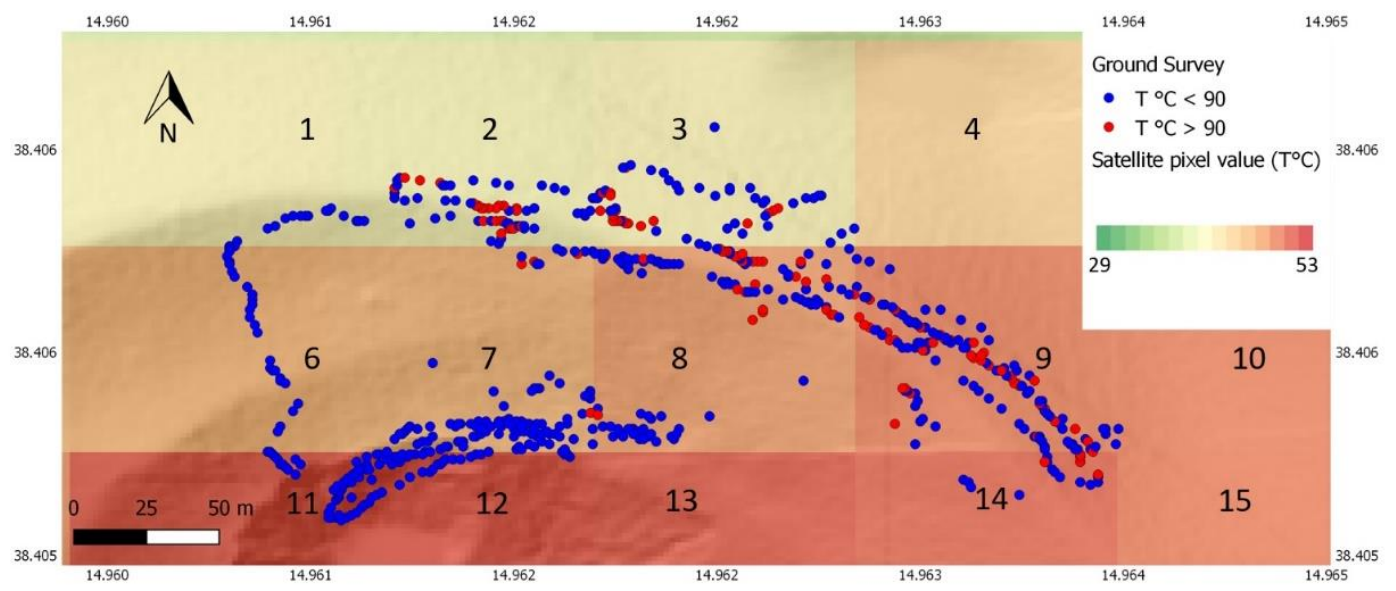

Figure 15. Ground survey point distribution inside the satellite images pixel boundary. Data of survey 15/09/2014 and ASTER acquisition on 19/09/2014. 


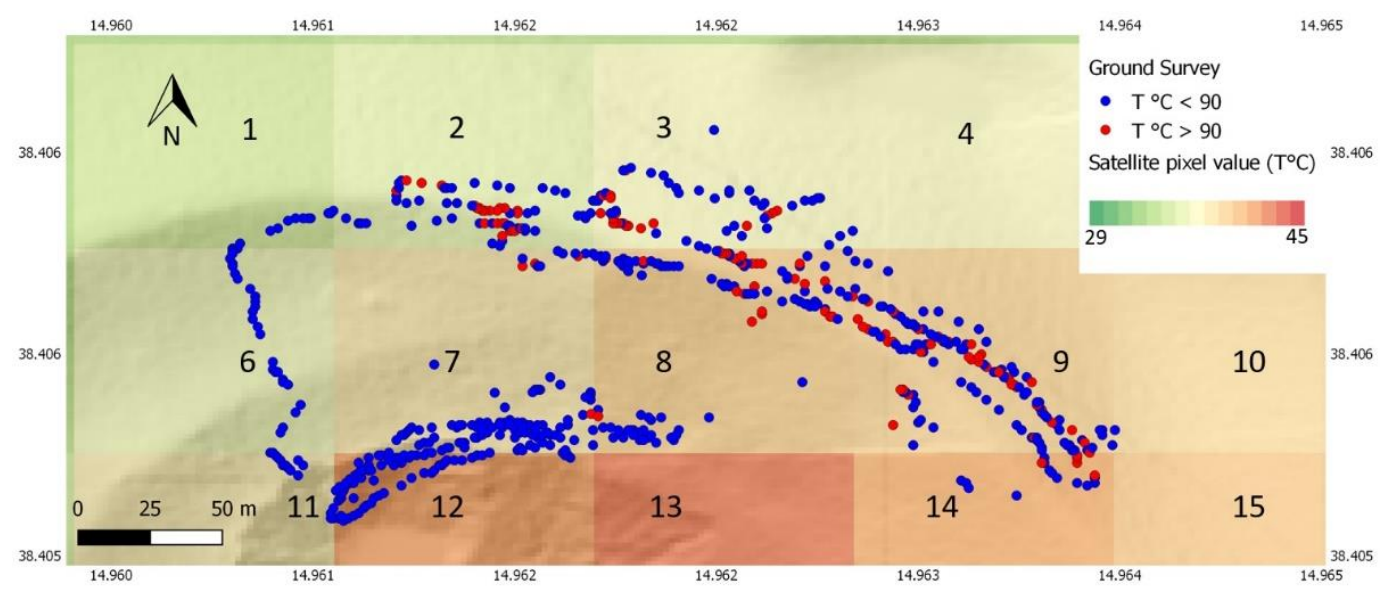

Figure 16. Ground survey point distribution inside the satellite images pixel boundary. Data of survey 15/09/2014 and L8 acquisition on 11/09/2014.

Table 6. Comparison between ground measurements and satellite estimation temperatures on La Fossa crater (Field campaign 15/09/2014, ASTER data 19/09/2014 and L8 data 11/09/2014).

\begin{tabular}{cccc}
\hline & Ground T $\left({ }^{\circ} \mathbf{C}\right)$ & ASTER T $\left({ }^{\circ} \mathbf{C}\right)$ & L8 T $\left({ }^{\circ} \mathbf{C}\right)$ \\
\hline 1 & 43.00 & $48.30 \pm 4.14$ & $35.60 \pm 5.62$ \\
2 & 87.00 & $48.50 \pm 4.12$ & $36.80 \pm 5.43$ \\
3 & 87.90 & $48.31 \pm 4.14$ & $37.90 \pm 5.28$ \\
4 & - & - & - \\
5 & - & - & - \\
6 & 37.64 & $52.62 \pm 3.80$ & $37.30 \pm 5.36$ \\
7 & 49.12 & $52.68 \pm 3.80$ & $39.00 \pm 5.13$ \\
8 & 69.90 & $50.06 \pm 4.00$ & $40.40 \pm 4.95$ \\
9 & 77.18 & $47.50 \pm 4.21$ & $40.10 \pm 4.99$ \\
10 & - & - & - \\
11 & 30.92 & $51.57 \pm 3.88$ & $38.70 \pm 5.17$ \\
12 & 42.00 & $49.84 \pm 4.01$ & $43.00 \pm 4.65$ \\
13 & & & \\
14 & 65.55 & $45.59 \pm 4.39$ & $42.30 \pm 4.73$ \\
15 & - & - & \\
\hline
\end{tabular}

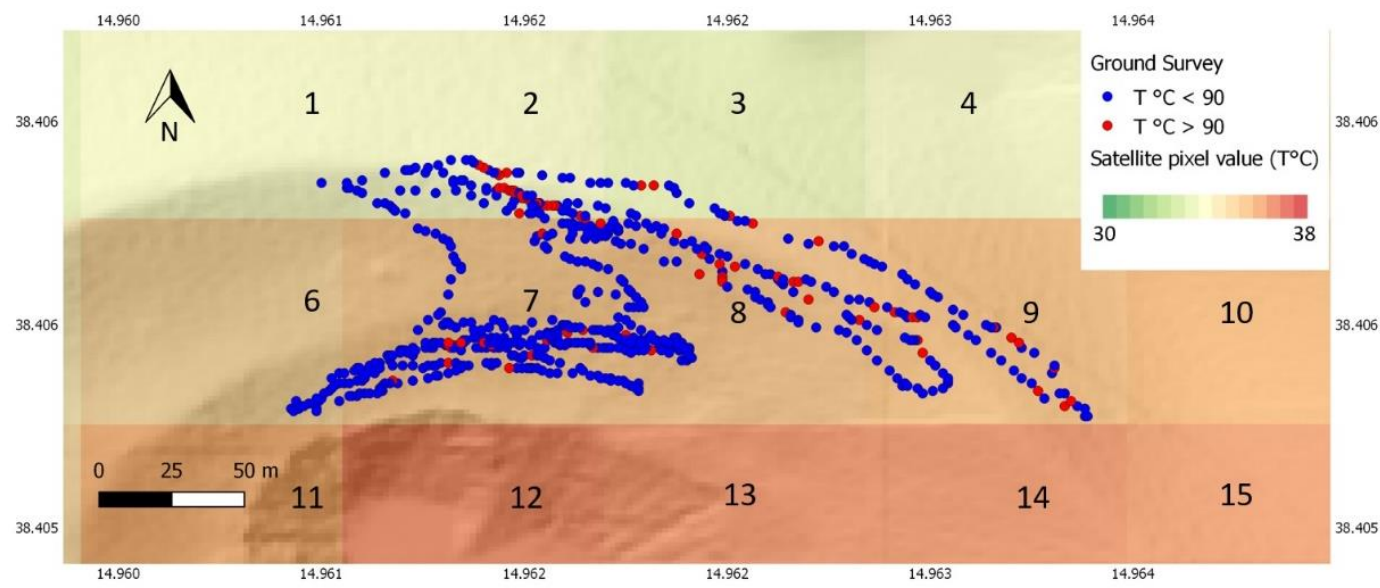

Figure 17. Ground survey point distribution inside the satellite images pixel boundary. Data of survey 26/04/2017 and L8 acquisition on 28/04/2017. 
Table 7. Comparison between ground measurements and satellite estimation temperatures on La Fossa crater (Field campaign 26/04/2017 and L8 data 28/04/2017).

\begin{tabular}{ccc}
\hline $\mathbf{N}^{\circ}$ Pixel & Ground T $\left({ }^{\circ} \mathbf{C}\right)$ & L8 T $\left({ }^{\circ} \mathbf{C}\right)$ \\
\hline 1 & 24.40 & $34.50 \pm 5.80$ \\
2 & 74.66 & $34.50 \pm 5.80$ \\
3 & 65.00 & $33.80 \pm 5.92$ \\
4 & - & - \\
5 & - & - \\
6 & 49.07 & $36.08 \pm 5.54$ \\
7 & 58.40 & $37.50 \pm 5.33$ \\
8 & 56.65 & $37.60 \pm 5.32$ \\
9 & 68.30 & $37.90 \pm 5.28$ \\
10 & - & - \\
11 & - & - \\
12 & - & - \\
13 & - & - \\
14 & - & - \\
15 & - & - \\
\hline
\end{tabular}

A first comment can be made about the spatial resolution of the measurements: "point" for ground data and "area" for data retrieved by satellite. Furthermore, it is important to remark that the average ground estimated temperature is higher than the temperature estimated by using satellite data. The ground measurements were collected near the hottest point where fumaroles were present and, as shown in Figures 14 and 18, their contribution is spread at satellite pixel scale.

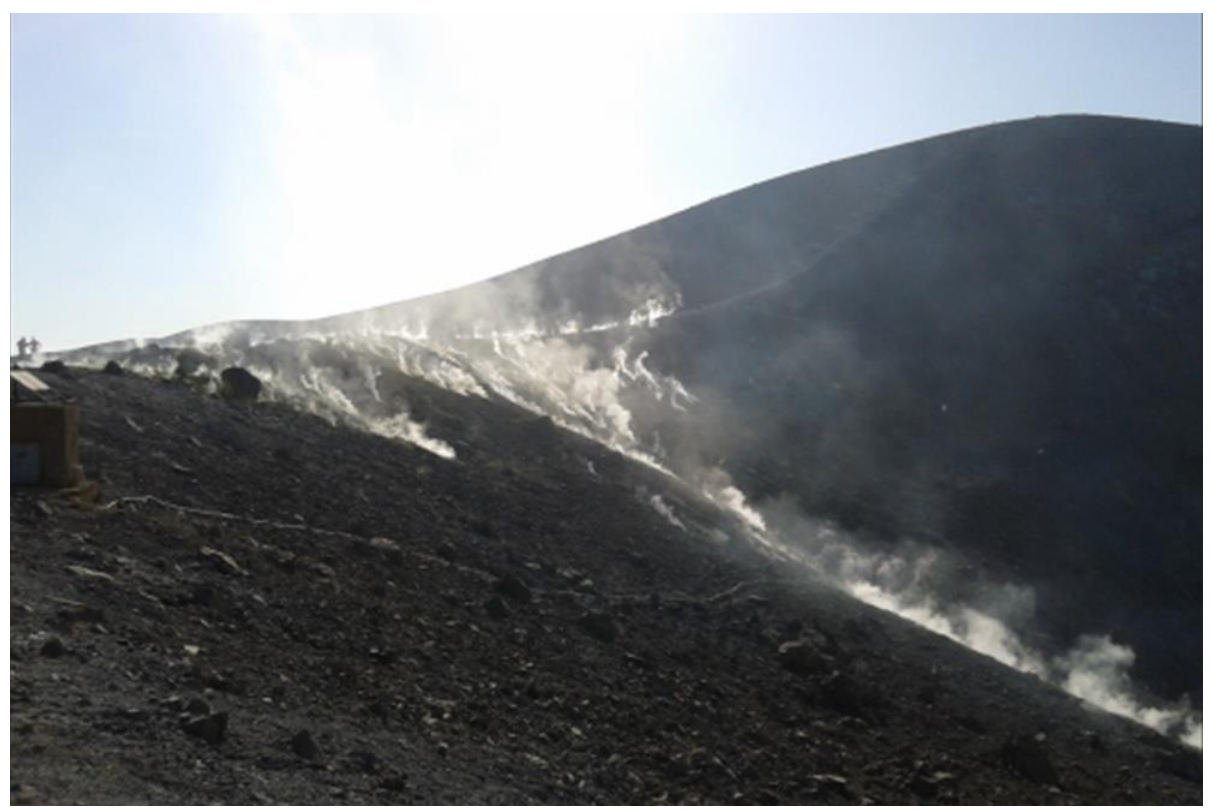

Figure 18. Fumaroles on the inner slope of the La Fossa cone. (Silvestri, M.-Photographer, 2015).

Similarly, the draping of the identified satellite pixels, overlapping the path followed during the field campaign held on the 15/09/2014 survey, is reported in Figure 19. The Comparison between ground measurements and satellite estimation temperatures in the mud pool "Fangaia", is reported in Table 8. 


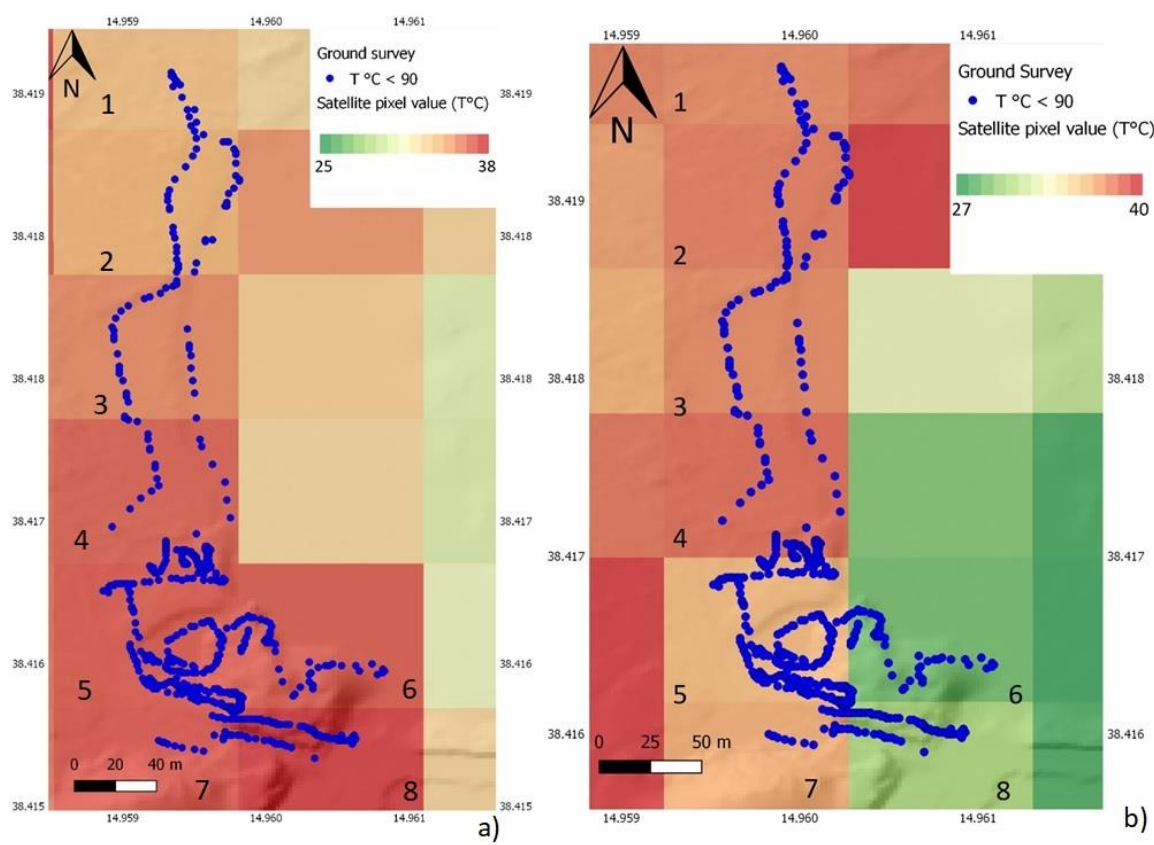

Figure 19. Ground survey point distribution inside the satellite images pixel boundary. Data of survey 15/09/2014 and L8 acquisition on 11/09/2014 (a) and ASTER acquisition 19/09/2014 (b).

Table 8. Comparison between ground measurements and satellite estimation temperatures in the mud pool "Fangaia".

\begin{tabular}{cccc}
\hline $\mathbf{N}^{\circ}$ Pixel & Ground T $\left({ }^{\circ} \mathbf{C}\right)$ & ASTER T $\left({ }^{\circ} \mathbf{C}\right)$ & L8 T $\left({ }^{\circ} \mathbf{C}\right)$ \\
\hline 1 & 29.44 & $37.95 \pm 5.27$ & $34.41 \pm 5.81$ \\
2 & 32.74 & $38.74 \pm 5.16$ & $34.80 \pm 5.75$ \\
3 & 34.20 & $36.61 \pm 5.46$ & $35.67 \pm 5.61$ \\
4 & 33.74 & $37.04 \pm 5.40$ & $36.52 \pm 5.48$ \\
5 & 38.97 & $42.00 \pm 4.76$ & $36.68 \pm 5.45$ \\
6 & 39.18 & $35.36 \pm 5.66$ & $36.63 \pm 5.46$ \\
7 & 40.59 & $42.06 \pm 4.76$ & $36.75 \pm 5.44$ \\
8 & 38.53 & $37.44 \pm 5.34$ & $37.22 \pm 5.37$ \\
\hline
\end{tabular}

During the field campaign on 16 July 2014, a nighttime IR map was produced by means of the Thermal Flir camera 620T (Figure 20). This map has been compared with the surface temperature map obtained by processing satellite acquisitions the day before (ASTER acquired on 15 July at 20:45 UTC). As the resampling of the satellite data results in a resolution of $90 \times 90 \mathrm{~m}$, a regularly-spaced $90 \times$ $90 \mathrm{~m}$ grid was created for the IR map to compare the temperatures of satellite images and IR ground image. For the comparison, we have considered as representative satellite pixels the ASTER and L8 pixels, since they have the hottest temperature compared to the other pixels: these hottest pixels are 2 for ASTER and 2 for L8 and they are fully overlapping. As reported in Table 9, the measured areas have a good correlation with the ground measurements. 

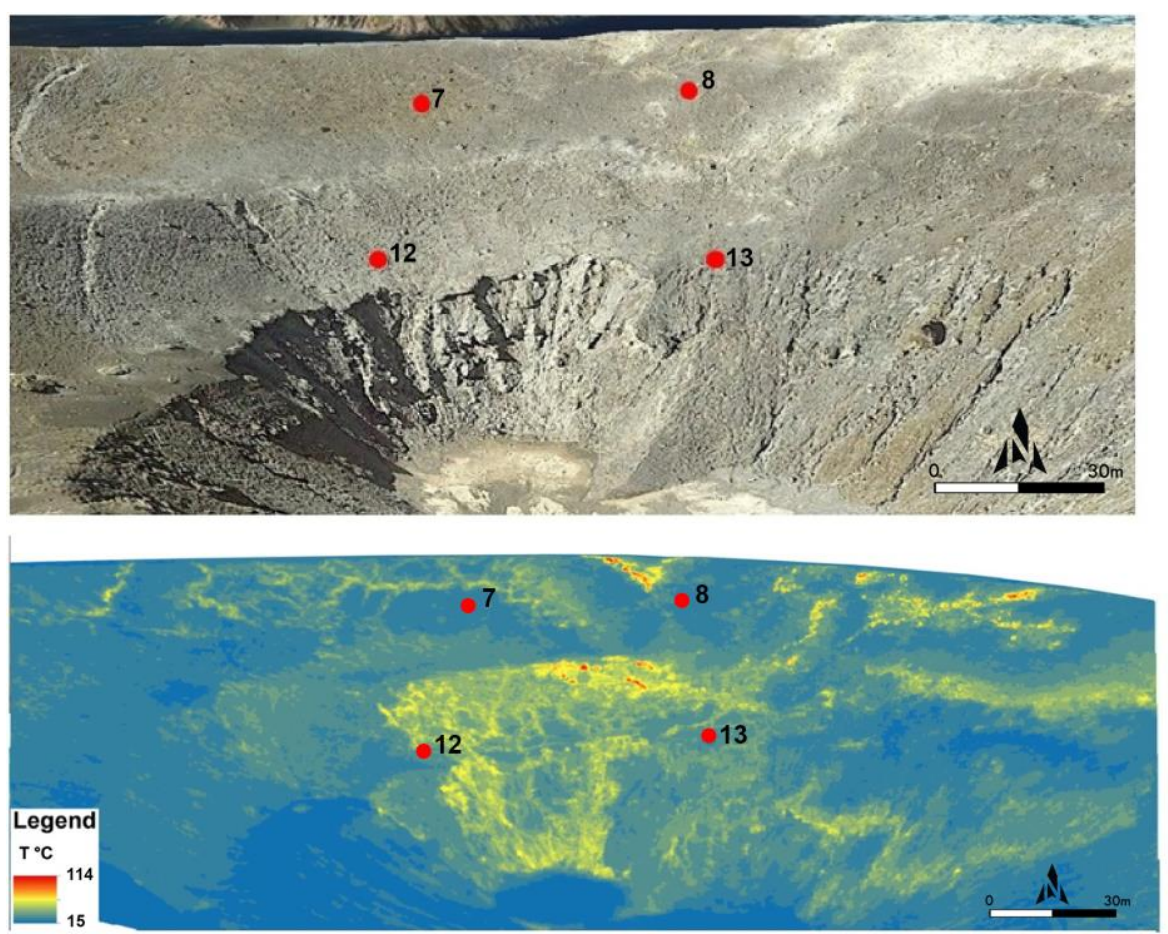

Figure 20. IR map acquired on La Fossa crater during the 16/07/2014 with a hand-held IR camera with satellite pixel. Red dots indicate the number of pixels as described in Figures 14-17.

Table 9. ASTER data of 15 July 2014 at 20:45 UTC, temperature measured with a hand-held IR camera and rescaled on ASTER pixel size, percentage of ground measured points falling in the $90 \times 90 \mathrm{~m}$ ASTER pixel.

\begin{tabular}{cccc}
\hline $\mathbf{N}^{\circ}$ Pixel & ASTER $\mathbf{T}\left({ }^{\circ} \mathbf{C}\right)$ & Thermal Camera $\mathbf{T}\left({ }^{\circ} \mathbf{C}\right)$ & \% of Thermal Camera Pixels \\
\hline 7 & 28.00 & 29.38 & 75 \\
12 & 26.23 & 26.86 & 100 \\
13 & 26.13 & 24.71 & 100 \\
8 & 28.61 & 27.28 & 75 \\
\hline
\end{tabular}

In order to constrain the hottest pixels in the La Fossa crater area, an analysis based on satellite data time series shows that the northern sector of the La Fossa crater inner slope is characterized by higher temperature (Figure 20) with respect to a wide area as represented in Figure 21. 


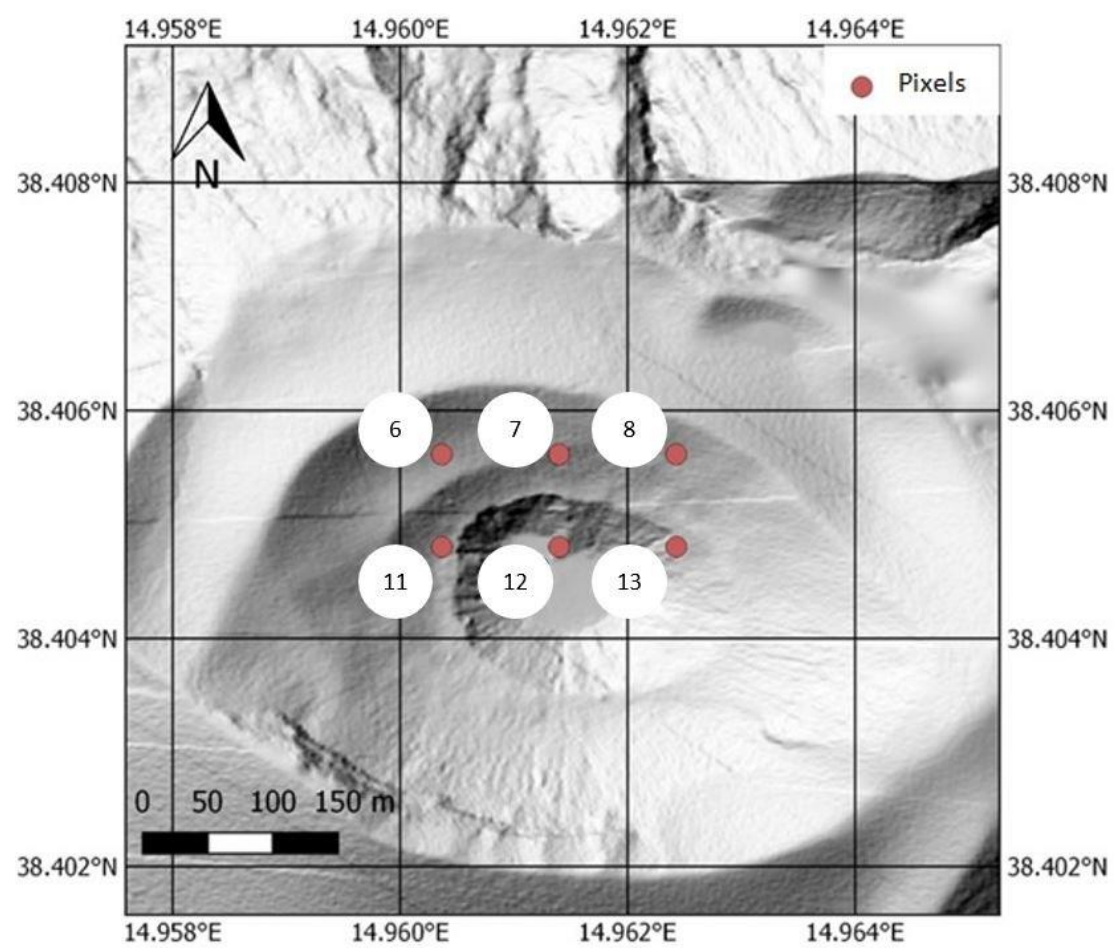

Figure 21. Red points represent the geographical position of the hottest pixels derived by time series satellite data for La Fossa crater.

By analysing ASTER time series, we pointed out that not all the pixels sensed by satellites are characterized by a significant thermal signature. A restricted number of pixels, highlighted by satellites, is systematically warmer than nearby. We determine that pixels numbered 7, 8, 12 and 13 are those for which the temperature is higher than the surrounding pixels, i.e., 192 count over 208 (Table 10 and Figure 22).

Table 10. Number of satellite (ASTER and L8) images for which the points are the hottest for the $L a$ Fossa area.

\begin{tabular}{ccc}
\hline $\mathbf{N}^{\circ}$ Pixel & ASTER Frequency & L8 Frequency \\
\hline 7 & 50 & 9 \\
8 & 35 & - \\
12 & 55 & 26 \\
13 & 17 & \\
\hline
\end{tabular}




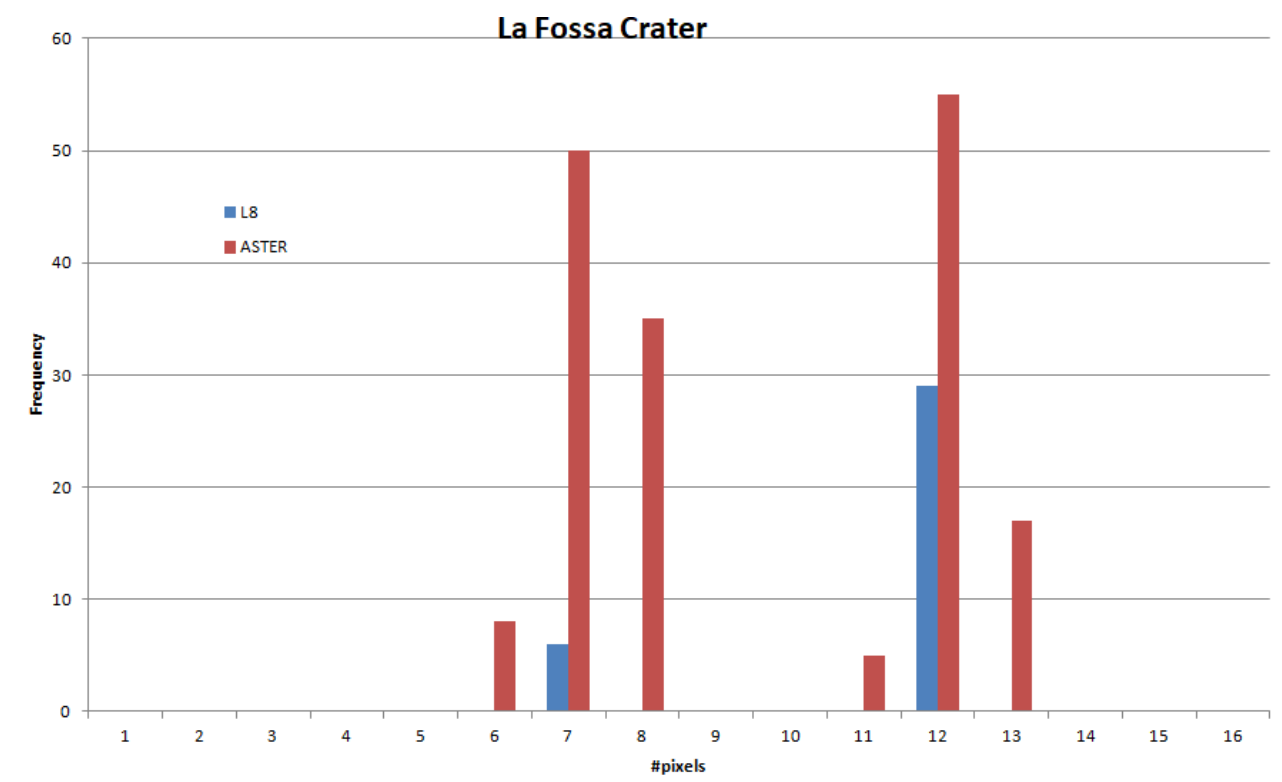

Figure 22. Histogram reports the numbering of the satellite pixel along the $x$-axis and the occurrence of the hottest pixels along the y-axis for La Fossa crater.

Similarly, the geographical positions of the hottest pixels derived by time series satellite data (Table 11) for the "Fangaia" mud pool were detected (Figures 23 and 24).

Table 11. Number of satellite (ASTER and L8) images for which the points are the hottest for "Fangaia" area.

\begin{tabular}{ccc}
\hline $\mathbf{N}^{\circ}$ Pixel & ASTER Frequency & L8 Frequency \\
\hline 5 & 20 & 6 \\
6 & 45 & 6 \\
7 & 8 & 5 \\
8 & 25 & 8 \\
\hline
\end{tabular}

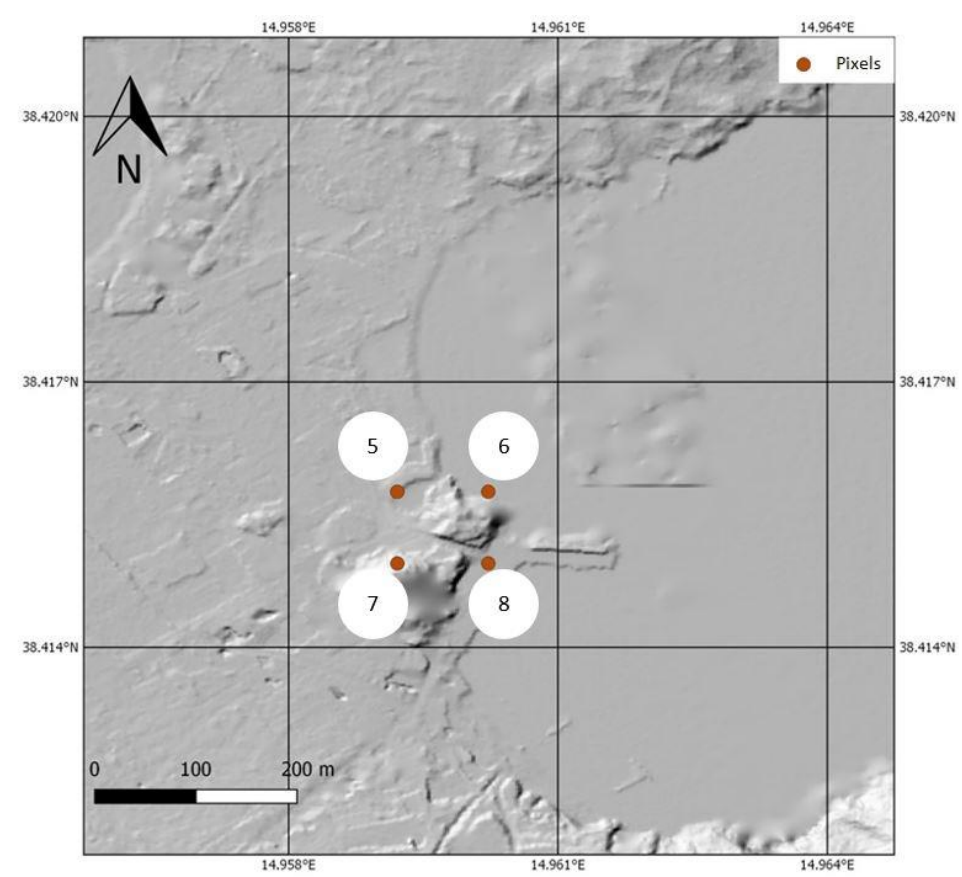

Figure 23. Red points represent the geographical position of the hottest pixels derived by time series satellite data for the "Fangaia"mud pool. 


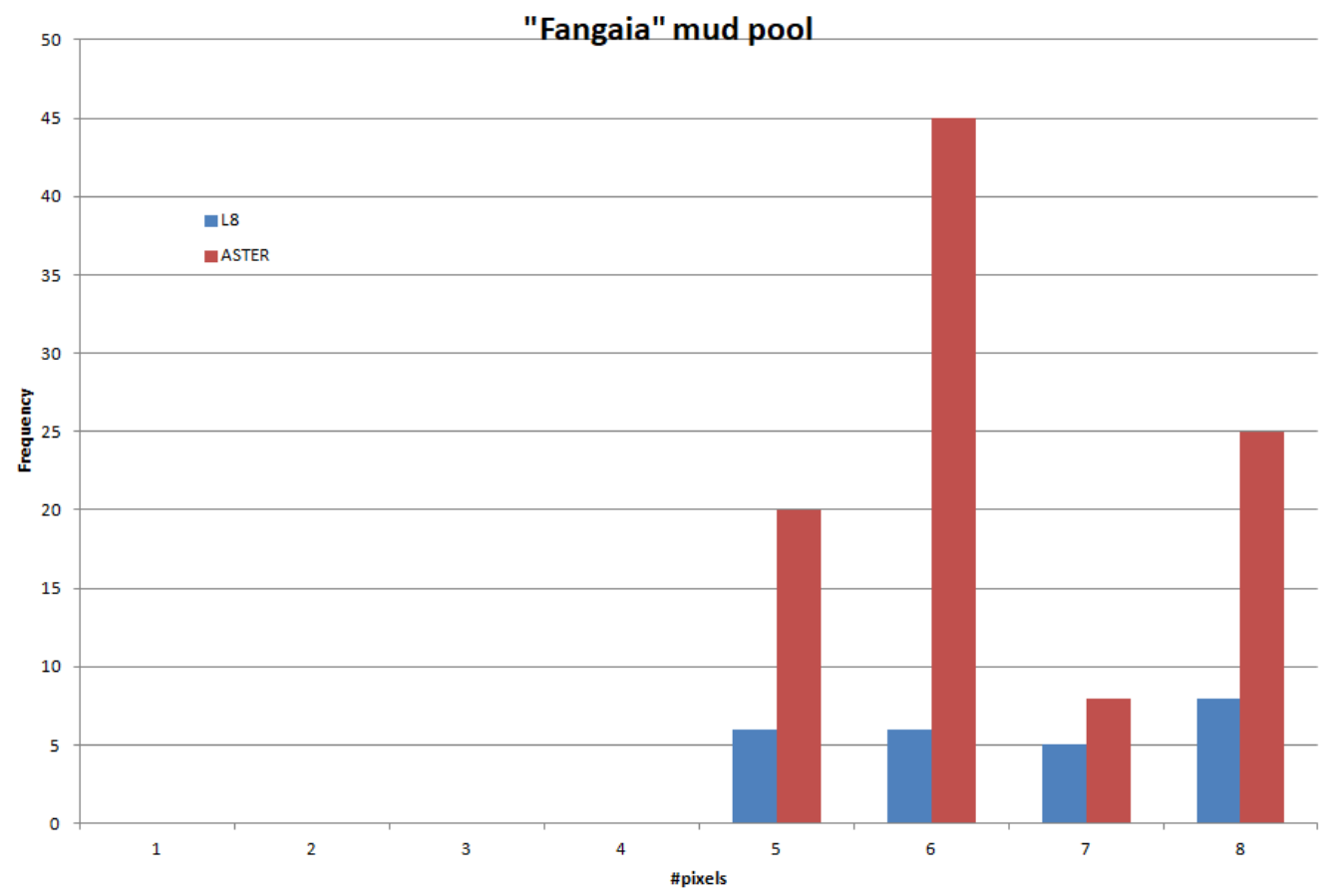

Figure 24. Histogram reports the numbering of the satellite pixel along the $x$-axis and the occurrence of the hottest pixels along the y-axis for "Fangaia" mud pool.

\subsection{Satellite Data Compared with Airborne Data}

In this section the discussion is based on the comparison between the retrieved ASTER thermal data series and the thermal data obtained by the ATM. The night-time satellite passes considered are those more temporally closed to the ATM airborne campaign. This results in ASTER acquisitions on 6 September and 22 September 2010. The comparison has been performed co-locating the ATM and ASTER processed data for ground temperature and dividing the "Fangaia" site by the La Fossa crater areas. Two different comparisons were performed. In a first comparison the mean of the temperature values retrieved for the two areas has been calculated considering the whole thermal anomalies derived by ATM and ASTER ground temperatures. Figure 25 shows the ATM thermal data and the areas containing the thermal anomalies considered to calculate the temperature means. In Table 12, the comparison of the mean temperatures retrieved is shown. The error in temperature values has been assigned considering the error of the processing algorithm. 


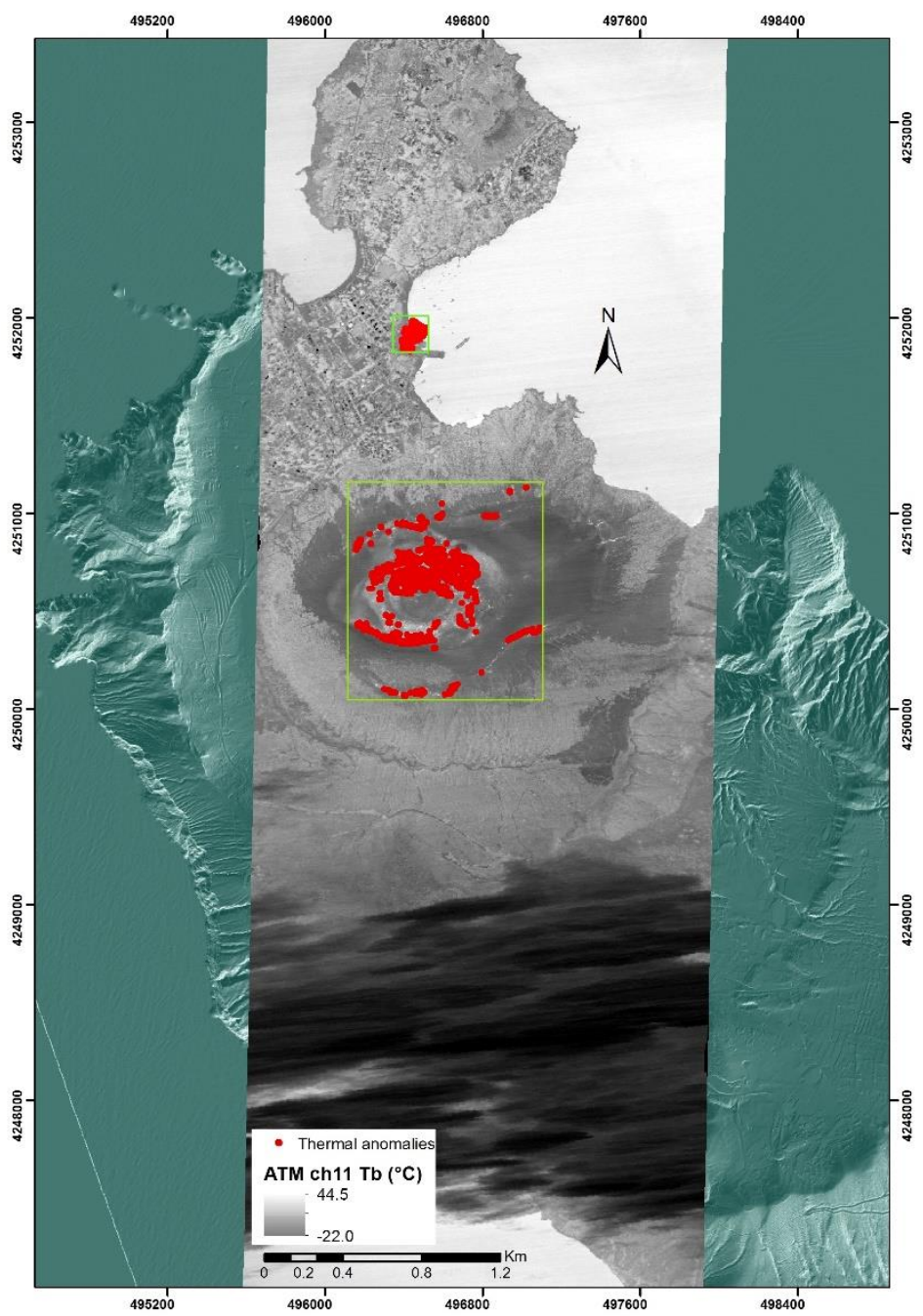

Figure 25. Thermal anomalies detected by ATM Thermal data (Red dots). The two green boxes are the area considered for the temperature meaning. Brightness temperature of ATM Thermal channel 11 over the Vulcano island is represented in grey scale with shaded relief represented in green.

Table 12. Comparison of the mean temperature derived from ATM and ASTER considering the areas of La Fossa crater and "Fangaia".

\begin{tabular}{cccc}
\hline \multirow{2}{*}{ Site } & ASTER Mean T $\left({ }^{\circ} \mathbf{C}\right)$ & ASTER Mean T $\left({ }^{\circ} \mathbf{C}\right)$ & ATM Mean T $\left({ }^{\circ} \mathbf{C}\right)$ \\
& $\mathbf{0 6 / 0 9 / 2 0 1 0}$ & $\mathbf{2 2 / 0 9 / 2 0 1 0}$ & $\mathbf{1 2 / 0 9 / 2 0 1 0}$ \\
\hline La Fossa Crater & $24.90 \pm 2.50$ & $24.30 \pm 2.40$ & $28.70 \pm 2.80$ \\
Fangaia & $26.70 \pm 2.70$ & $25.70 \pm 2.60$ & $27.20 \pm 2.70$ \\
\hline
\end{tabular}

The comparison highlights, as expected, that ATM has higher temperature values than ASTER. In the "Fangaia" area there is quite good agreement between the ASTER acquired on 6 September and the ATM-retrieved temperature (Figure 26). In the La Fossa Crater area, the ATM-derived temperature is higher for both ASTER acquisitions. In order to better understand such difference, a second comparison has been performed. The comparison of ASTER acquired on 6 September and ATM thermal anomalies has been performed pixel by pixel for the La Fossa Crater (Figure 26). Many thermal anomalies derived from ATM cannot be discriminated at an ASTER ground sampling resolution of $90 \mathrm{~m}$, which is too low to capture small fumarolic areas, which instead ATM airborne data with $3 \mathrm{~m}$ of ground resolution can identify. In order to make a closer comparison, the ATM mean temperature has been recalculated pixel by pixel and only the ASTER and ATM common pixels are considered. Referring to Figure 26, we have 
obtained an average value of $25.8 \pm 1.4^{\circ} \mathrm{C}$ from 6 September ASTER data and an average temperature of $27.6 \pm 2.4{ }^{\circ} \mathrm{C}$ from ATM data.
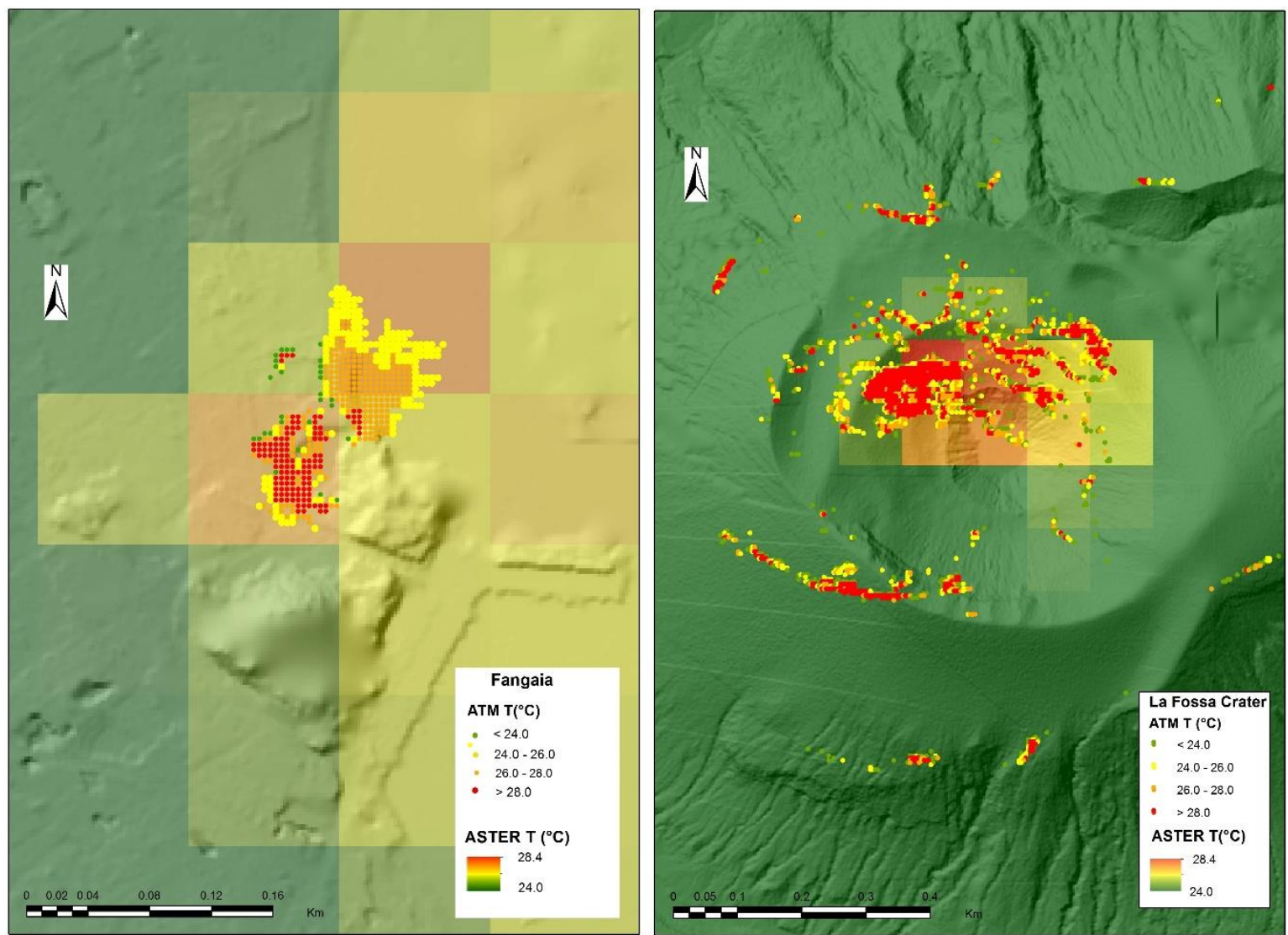

Figure 26. ASTER acquired on 6 September and ATM-retrieved temperature comparison of the "Fangaia" area (left) and La Fossa Crater (right).

\section{Conclusions}

This study is based on the comparison among satellite data with measurements collected in different campaigns (airborne and ground). By analysing 2000-2017 spaceborne remotely sensed time series data of surface temperature covering the whole island, we have detected hot pixels and used them as focal points. Assuming that all pixels on the island are affected by the same seasonal conditions, the hottest pixels identified will be warmer independently of seasonal and daily variations. During the daytime, the reflected solar radiation is difficult to remove from thermal channels. Moreover, the error caused by the solar correction term can affect the retrieval accuracy, especially under low reflectance in thermal infrared regions. Therefore, in our analysis, the reflected solar radiation was neglected. Considering that thermal anomalies may occur on the ground surface with low intensity, an accurate surface thermal mapping should rely only on nighttime remotely sensed images rather than daytime measurements.

The multiscale approach has been offered by measurement of the surface temperature data collected during field campaigns and remotely sensed data from airborne and spaceborne platforms. The multitemporal characteristics have been approached by comparing long-term time series (satellite data) and discontinuous measurements (ground and airborne campaigns). The potential of these new applications could improve the results of direct monitoring systematically performed for volcanic surveillance since 1990 by a network of stations for ground temperature measurements. Surface temperature estimated by remote sensing data has been validated using independent measurements provided by the Oplao website. 
In order to validate the accuracy of satellite surface temperature, we compared ASTER/L8 data, close in time, to the airborne and ground campaigns, paying attention to the hottest pixels highlighted in the above-mentioned procedure. The statistical analysis through Pearson correlation index, NSE and NB has shown a strong agreement among the data with a Pearson correlation index varying from 0.8956 to 0.9276 . At the same time, the NSE and NB indices show very high correlation considering the values ranging from 0.1117 to 0.1377 and from -0.0157 to 0.0531 , respectively. The reliability of the surface temperature retrieval methodology has allowed to compare these values with those acquired by field and airborne measurements revealing differences of about $5 \%$ with nighttime acquisition and up to $50 \%$ with daytime acquisition.

After detecting the temperature changes affecting the fumaroles areas, a further outcome of this study would be to extend the comparison of data obtained through direct and indirect acquisition to the areas affected by a diffused thermal release. With this constraint the thermal monitoring of heat flux of La Fossa cone, emitted from both the fumaroles and the diffuse outgassing, could provide important support for the detection of the early warning phenomena that precede a volcanic crisis. Moreover, the geophysical and geochemical signals for the last 29 years have been located within the La Fossa caldera, the summit area of the La Fossa Cone and the village located at its foot. Indeed, during the monitored period, the interval of time with anomalous energy output always correlated with the temperature change in the natural volatile emanations, and they could all be updated by the continuous monitoring of the summit fumaroles.

In order to highlight the main changes in the thermal release from a solphataric area, it is suggested to implement a systematic procedure based on the integration and comparison of the surface temperatures retrieved using remote sensing with direct method measurements.

In this work we have analysed the possibility of observing and estimating thermal anomalies on Vulcano island using a multiscale and multitemporal approach. By considering the reliability of the proposed approach, the authors believe that it can be also used for monitoring volcanic areas where ground networks are not present or because the volcanoes lie in remote areas.

Author Contributions: M.S., I.S.D. and M.F.B. conceived the idea and wrote the manuscript with contributions from all authors. M.S, F.R. and M.M. processed satellite data to retrieve the surface temperature, analysed them and import products in a GIS environment. A.P. and I.S.D. performed ground field campaigns and thermal camera measurements on La Fossa crater and the "Fangaia" mud pool. L.C., C.S., V.L. performed the airborne field campaign, processed airborne data and analysed them. All authors contributed to the ideas, writing, and discussion.

Funding: This research received no external funding.

Acknowledgments: The ASTER L1T and ASTER05 data were retrieved from the online Data tool, courtesy of the NASA EOSDIS Land Processes Distributed Active Archive Center (LP DAAC), USGS/Earth Resources Observation and Science (EROS) Center, Sioux Falls, South Dakota, [https:/ / earthexplorer.usgs.gov/]. L8 L1T processing, archiving, and distribution are performed by the USGS. Airborne data were acquired by the Italian Coast Guard under the INGV-ICG 2009 memorandum of understanding. I.S.D. is particularly grateful to Manfredi Longo for helping during the preparation and execution of the first field campaign and to Antonina Lisa Gagliano for processing and mapping the ground data. A special thanks to Vito Romaniello for helping in statistical analysis of satellite and meteorological data. Constructive comments from three reviewers helped to improve the manuscript. Special thanks are extended to Alexander Shaw and his wife Serena Tramonti for checking the English.

Conflicts of Interest: The authors declare no conflict of interest.

\section{References}

1. Inguaggiato, S.; Diliberto, I.S.; Federico, C.; Paonita, A.; Vita, F. Review of the evolution of geochemical monitoring, networks and methodologies applied to the volcanoes of the Aeolian Arc (Italy). Earth-Sci. Rev. 2018, 176, 241-276. [CrossRef]

2. Sano, Y.; Kagoshima, T.; Takahata, N.; Nishio, Y.; Roulleau, E.; Pinti, D.L.; Fischer, T.P. Ten-year helium anomaly prior to the $2014 \mathrm{Mt}$ Ontake eruption. Sci. Rep. 2015, 5, 13069. [CrossRef] 
3. Ohno, M.; Utsugi, M.; Mori, T.; Kita, I.; Kagiyama, T.; Tanaka, Y. Temporal variation in the chemical composition $\left(\mathrm{HCl} / \mathrm{SO}_{2}\right)$ of volcanic gas associated with the volcanic activity of Aso volcano, Japan. Earth Planets Sp. 2013, 65, e1. [CrossRef]

4. Liuzzo, M.; Gurrieri, S.; Giudice, G.; Giuffrida, G. Ten years of soil $\mathrm{CO}_{2}$ continuous monitoring on Mt. Etna: Exploring the relationship between processes of soil degassing and volcanic activity. Geochem. Geophys. Geosyst. 2013, 14. [CrossRef]

5. Aiuppa, A.; Federico, C.; Gaetano, G.; Giovanni, G.; Guida, R.; Gurrieri, S.; Liuzzo, M.; Moretti, R.; Papale, P. The 2007 eruption of Stromboli Volcano: Insights from real-time measurement fo the volcanic gas plume $\mathrm{CO}_{2} / \mathrm{SO}_{2}$ ratio. J. Volcanol. Geotherm. Res. 2009, 182, 221-230. [CrossRef]

6. Montalto, A. Signs of potential renewal of eruptive activity at La Fossa (Vulcano, Aeolian Islands). Bull. Volcanol. 1996, 57, 483-492. [CrossRef]

7. Italiano, F.; Pecoraino, G. Steam output from fumaroles of an active volcano: Tectonic and magmatic-hydrothermal controls on the degassing system at Vulcano (Aeolian arc). J. Geophys. Res. 1998, 103, 29829-29842. [CrossRef]

8. Aubert, M.; Alparone, S. Variation d'origine sismique du flux de chaleur convectif dans La Fossa de Vulcano (Italie). C. R. L'Acad. Sci. Ser. IIA Earth Planet. Sci. 2000, 330, 603-610. [CrossRef]

9. Lowenstern, J.B.; Smith, R.B.; Hill, D.P. Monitoring super-volcanoes: Geophysical and geochemical signals at Yellowstone and other large caldera systems. Philos. Trans. R. Soc. Lond. A Math. Phys. Eng. Sci. 2006, 364, 2055-2072. [CrossRef]

10. Milluzzo, V.; Cannata, A.; Alparone, S.; Gambino, S.; Hellwegg, M.; Montalto, P.; Cammarata, L.; Diliberto, I.S.; Gresta, S.; Liotta, M.; et al. Tornillos at Vulcano: Clues to the dynamics of the hydrothermal system. J. Volcanol. Geotherm. Res. 2010. [CrossRef]

11. Cannata, A.; Diliberto, I.S.; Alparone, S.; Gambino, S.; Gresta, S.; Liotta, M.; Montalto, P. Multiparametric approach in investigating volcano-hydrothermal systems: The case study of Vulcano (Aeolian Islands, Italy). Pure Appl. Geophys. 2012, 169, 167-182. [CrossRef]

12. Bukumirovich, T.; Italiano, F.; Nuccio, P.M. The evolution of a dynamic geological system: The support of a GISfor geochemical measurements at the fumarole field of Vulcano, Italy. J. Volcanol. Geotherm. Res. 1997, 79, 253-263. [CrossRef]

13. Diliberto, I.S. Long-term monitoring on a closed-conduit volcano: A 25year long time-series of temperatures recorded at La Fossa cone (Vulcano Island, Italy), ranging from $250{ }^{\circ} \mathrm{C}$ to $520^{\circ} \mathrm{C}$. J. Volcanol. Geotherm. Res. 2017. [CrossRef]

14. Diliberto, I.S. Time series analysis of high temperature fumaroles monitored on the island of Vulcano (Aeolian Archipelago, Italy). J. Volcanol. Geotherm. Res. 2013, 264, 150-163. [CrossRef]

15. Diliberto, I.S. Long-term variations of fumaroles temperatures on Vulcano Island (Italy). Ann. Geophys. 2011, 54. [CrossRef]

16. Bonaccorso, A.; Bonforte, A.; Gambino, S. Thermal expansion-contraction and slope instability of a fumaroles field inferred from geodetic measurements at Vulcano. Bull. Volcanol. 2010, 72, 791-801. [CrossRef]

17. Calvari, S.; Lodato, L.; Spampinato, L. Monitoring active volcanoes using a handheld thermal camera. Thermosense 2004, 5405, 199-210.

18. Chiodini, G.; Vilardo, G.; Augusti, V.; Granieri, D.; Caliro, S.; Minopoli, C.; Terranova, C. Thermal monitoring of hydrothermal activity by permanent infrared automatic stations: Results obtained at Solfatara di Pozzuoli, Campi Flegrei (Italy). J. Geophys. Res. Solid Earth 2007, 112. [CrossRef]

19. Walter, T.R.; Legrand, D.; Granados, H.D.; Reyes, G.; Arámbula, R. Volcanic eruption monitoring by thermal image correlation: Pixel offsets show episodic dome growth of the Colima volcano. J. Geophys. Res. Solid Earth 2013, 118, 1408-1419. [CrossRef]

20. Patrick, M.R.; Kauahikaua, J.; Orr, T.; Davies, A.; Ramsey, M. Operational thermal remote sensing and lava flow monitoring at the Hawaiian Volcano Observatory. Geol. Soc. Lond. Spec. Publ. 2016, 426, 489-503. [CrossRef]

21. Mia, M.B.; Fujimitsu, Y.; Nishijima, J. Thermal Activity Monitoring of an Active Volcano Using Landsat 8/OLI-TIRS Sensor Images: A Case Study at the Aso Volcanic Area in Southwest Japan. Geosciences 2017, 7, 118. [CrossRef] 
22. Sobrino, J.A.; Del Frate, F.; Drusch, M.; Jiménez-Muñoz, J.C.; Manunta, P.; Regan, A. Review of thermal infrared applications and requirements for future high-resolution sensors. IEEE Trans. Geosci. Remote Sens. 2016, 54, 2963-2972. [CrossRef]

23. Schmetz, J.; Pili, P.; Tjemkes, S.; Just, D.; Kerkmann, J.; Rota, S.; Ratier, A. An introduction to Meteosat second generation (MSG). Bull. Am. Meteorol. Soc. 2002, 83, 977-992. [CrossRef]

24. Sun, D.; Pinker, R.T. Estimation of land surface temperature from a Geostationary Operational Environmental Satellite (GOES-8). J. Geophys. Res. Atmos. 2003, 108. [CrossRef]

25. Wan, Z.; Snyder, W. MODIS Land-Surface Temperature Algorithm Theoretical Basis Document (LST ATBD), Version 3.2. In Institute for Computational Earth System Science; University of California: Santa Barbara, CA, USA, 1996.

26. Li, Z.-L.; Becker, F. Feasibility of land surface temperature and emissivity determination from AVHRR data. Remote Sens. Environ. 1993, 85, 67-85. [CrossRef]

27. Donlon, C.; Berruti, B.; Buongiorno, A.; Ferreira, M.H.; Féménias, P.; Frerick, J.; Goryl, P.; Klein, U.; Laur, H.; Mavrocordatos, C.; et al. The Global Monitoring for Environment and Security (GMES) Sentinel-3 mission. Remote Sens. Environ. 2012, 120, 37-57. [CrossRef]

28. Buongiorno, M.F.; Pieri, D.; Silvestri, M. Thermal analysis of volcanoes based on 10 years of ASTER data on Mt. Etna. In Thermal Infrared Remote Sensing; Springer: Dordrecht, The Netherlands, 2013; pp. 409-428.

29. Roy, D.P.; Wulder, M.A.; Loveland, T.R.; Woodcock, C.E.; Allen, R.G.; Anderson, M.C.; Helder, D.; Irons, J.R.; Johnson, D.M.; Kennedy, R. Landsat-8: Science and product vision for terrestrial global change research. Remote Sens. Environ. 2014, 145, 154-172. [CrossRef]

30. Harris, A.; Butterworth, A.; Carlton, R.; Downey, I.; Miller, P.; Navarro, P.; Rothery, D. Low-cost volcano surveillance from space: Case studies from Etna, Krafla, Cerro Negro, Fogo, Lascar and Erebus. Bull. Volcanol. 1997, 59, 49-64. [CrossRef]

31. Lombardo, V.; Harris, A.J.L.; Calvari, S.; Buongiorno, M.F. Spatial variations in lava flow field thermal structure and effusion rate derived from very high spatial resolution hyperspectral (MIVIS) data. J. Geophys. Res. Solid Earth 2009, 114. [CrossRef]

32. Harris, A.J.; Rose, W.I.; Flynn, L.P. Temporal trends in lava dome extrusion at Santiaguito 1922-2000. Bull. Volcanol. 2003, 65, 77-89.

33. Van Manen, S.M.; Dehn, J.; Blake, S. Satellite thermal observations of the Bezymianny lava dome 1993-2008: Precursory activity, large explosions, and dome growth. J. Geophys. Res. Solid Earth 2010, 115. [CrossRef]

34. Higgins, J.; Harris, A. VAST: A program to locate and analyse volcanic thermal anomalies automatically from remotely sensed data. Comput. Geosci. 1997, 23, 627-645. [CrossRef]

35. Harris, A.J.L.; Wright, R.; Flynn, L.P. Remote Monitoring of Mount Erebus Volcano, Antarctica, Using Polar Orbiters: Progress and Prospects. Int. J. Remote Sens. 1999, 20, 3051-3071. [CrossRef]

36. Wan, Z.; Wang, P.; Li, X. Using MODIS land surface temperature and normalized difference vegetation index products for monitoring drought in the southern Great Plains, USA. Int. J. Remote Sens. 2004, 25, 61-72. [CrossRef]

37. Wooster, M.J.; Rothery, D.A. Thermal monitoring of Lascar Volcano, Chile, using infrared data from the along-track scanning radiometer: A 1992-1995 time series. Bull. Volcanol. 1997, 58, 566-579. [CrossRef]

38. Hogda, K.A.; Karlsen, S.R.; Solheim, I. Climatic change impact on growing season in Fennoscandia studied by a time series of NOAA AVHRR NDVI data. In Proceedings of the IEEE 2001 International Geoscience and Remote Sensing Symposium, Sydney, NSW, Australia, 9-13 July 2001.

39. Locardi, E.; Nappi, G. Tettonica e vulcanismo recente nell'isola di Lipari. Bollettino Della Societa Geologica Italiana 1979, 98, 447-456.

40. Mazzuoli, R.; Tortorici, L.; Ventura, G. Oblique rifting in Salina; Lipari and Vulcano islands (Aeolian islands; southern Italy). Terra Nova 1995, 7, 444-452. [CrossRef]

41. Ventura, G. Tectonics, structural evolution and caldera formation on Vulcano Island (Aeolian Archipelago; southern Tyrrhenian Sea). J. Volcanol. Geotherm. Res. 1994, 60, 207-224. [CrossRef]

42. Ventura, G. Relazioni fra Tettonica e Vulcanismo Nelle Isole del Tirreno Meridionale (Eolie, Ustica). Ph.D. Thesis, University of Cosenza, Rende, Italy, 1995.

43. Ventura, G. Kinematics of the Aeolian volcanism (Southern Tyrrhenian Sea) from geophysical and geological data. Geol. Soc. Lond. Mem. 2013, 37, 3-11. [CrossRef] 
44. Lanzafame, G.; Bousquet, J.C. The Maltese escarpment and its extension from Mt. Etna to Aeolian Islands (Sicily): Importance and evolution of a lithosphere discontinuity. Acta Vulcanol. 1997, 9, 113-120.

45. Ventura, G.; Vilardo, G.; Milano, G.; Pino, N.A. Relationships among crustal structure; volcanism and strike-slip tectonics in the Lipari-Vulcano volcanic complex (Aeolian Islands; Southern Tyrrhenian Sea, Italy). Phys. Earth Planet. Inter. 1999, 116, 31-52. [CrossRef]

46. De Astis, G.; Ventura, G.; Vilardo, G. Geodynamic significance of the Aeolian volcanism (Southern Tyrrhenian Sea; Italy) in light of structural; seismological, and geochemical data. Tectonics 2003, 22. [CrossRef]

47. Silvestri, M.; Arcomano, G.; Pruiti, L.; Valentini, E. Campagna di misure a Lipari per la calibrazione di dati iperspettrali da sensore aereo. Rapporti Tecnici INGV 2014, 275, 1-30.

48. Keller, J. The island of Vulcano. Rendiconti della Societa Italiana di Mineralogia e Petrologia 1980, 36, 368-413.

49. De Astis, G.; Lucchi, F.; Dellino, P.; La Volpe, L.; Tranne, C.A.; Frezzotti, M.L.; Peccerillo, A. Geology, volcanic history and petrology of Vulcano (central Aeolian archipelago). Geol. Soc. Lond. Mem. 2013, 37, 281-349. [CrossRef]

50. De Astis, G.; Dellino, P.; La Volpe, L.; Lucchi, F.; Tranne, C.A. Geological Map of the Island of Vulcano (Aeolian Islands); Annals of Geophysics: Bari, Italy, 2006.

51. Revil, A.; Finizola, A.; Piscitelli, S.; Rizzo, E.; Ricci, T.; Crespy, A.; Bolève, A. Inner structure of La Fossa di Vulcano (Vulcano Island, southern Tyrrhenian Sea, Italy) revealed by high-resolution electric resistivity tomography coupled with self-potential, temperature, and $\mathrm{CO}_{2}$ diffuse degassing measurements. J. Geophys. Res. Solid Earth 2008, 113. [CrossRef]

52. Frazzetta, G.; Lanzafame, G.; Villari, L. Deformazioni e tettonica attiva a Lipari e Vulcano (Eolie). Mem. Soc. Geol. It. 1982, 24, 293-297.

53. Continisio, R.; Ferrucci, F.; Gaudiosi, G.; Lo Bascio, D.; Ventura, G. Malta escarpment and Mt. Etna: Early stages of an asymmetric rifting process? Evidences from geophysical and geological data. Acta Vulcanol. 1997, 9, 45-54.

54. Keller, J. Die vulkanologisch-magmatologische Evolution der Insel Vulcano (Aeolische Inseln/Sizilien). 1972. Available online: http:/ / www.zobodat.at/pdf/Berichte-naturf-Ges-Freiburg-Br_57_0033-0067.pdf (accessed on 1 January 2018).

55. Frazzetta, G.; Gillot, P.Y.; La Volpe, L.; Sheridan, M.F. Volcanic hazards at Fossa of Vulcano: Data from the last 6000 years. Bull. Volcanol. 1984, 47, 105-124. [CrossRef]

56. Dellino, P.; De Astis, G.; La Volpe, L.; Mele, D.; Sulpizio, R. Quantitative hazard assessment of phreatomagmatic eruptions at Vulcano (Aeolian Islands, Southern Italy) as obtained by combining stratigraphy, event statistics and physical modelling. J. Volcanol. Geotherm. Res. 2011, 201, 364-384. [CrossRef]

57. Capasso, G.; Favara, R.; Inguaggiato, S. Chemical features and isotopic composition of gaseous manifestations on Vulcano Island, Aeolian Islands, Italy: An interpretative model of fluid circulation. Geochimica et Cosmochimica Acta 1997, 61, 3425-3440. [CrossRef]

58. Inguaggiato, S.; Calderone, L.; Inguaggiato, C.; Mazot, A.; Morici, S.; Vita, F. Long-time variation of soil $\mathrm{CO}_{2}$ fluxes at the summit crater of Vulcano (Italy). Bull. Volcanol. 2012, 74, 1859-1863. [CrossRef]

59. Inguaggiato, S.; Mazot, A.; Diliberto, I.S.; Inguaggiato, C.; Madonia, P.; Rouwet, D.; Vita, F. Total CO 2 output from Vulcano island (Aeolian Islands, Italy). Geochem. Geophys. Geosyst. 2012, 13. [CrossRef]

60. Inguaggiato, S.; Vita, F.; Cangemi, M.; Mazot, A.; Sollami, A.; Calderone, L.; Jacome Paz, M.P. Stromboli volcanic activity variations inferred by fluids geochemistry observations: Sixteen years of continuous soil $\mathrm{CO}_{2}$ fluxes monitoring (2000-2015). Chem. Geol. 2017. [CrossRef]

61. Nuccio, P.M.; Paonita, A.; Sortino, F. Geochemical mixing between magmatic and hydrothermal gases: The case of Vulcano Island, Italy. Earth Planet. Sci. Lett. 1999, 167, 321-333. [CrossRef]

62. Harris, A.J.L.; Lodato, L.; Dehn, J.; Spampinato, L. Thermal characterization of the Vulcano fumarole field. Bull. Volcanol. 2009, 71, 441-458. [CrossRef]

63. Granieri, D.; Carapezza, M.L.; Chiodini, G.; Avino, R.; Caliro, S.; Ranaldi, M.; Tarchini, L. Correlated increase in $\mathrm{CO}_{2}$ fumarolic content and diffuse emission from La Fossa crater (Vulcano, Italy): Evidence of volcanic unrest or increasing gas release from a stationary deep magma body? Geophys. Res. Lett. 2006, 33. [CrossRef]

64. Aubert, M.; Diliberto, S.; Finizola, A.; Chébli, Y. Double origin of hydrothermal convective flux variations in the Fossa of Vulcano (Italy). Bull. Volcanol. 2008, 70, 743-751. [CrossRef] 
65. Yamaguchi, Y.; Kahle, A.; Tsu, H.; Kawakami, T.; Pniel, M. Overview of Advanced Spaceborne Thermal Emission and Reflection Radiometer (ASTER). IEEE Trans. Geosci. Remote Sens. 1998, 36, 1062-1071. [CrossRef]

66. Abrams, M.; Tsu, H.; Hulley, G.; Iwao, K.; Pieri, D.; Cudahy, T.; Kargel, J. The advanced spaceborne thermal emission and reflection radiometer (ASTER) after fifteen years: Review of global products. Int. J. Appl. Earth Obs. Geoinf. 2015, 38, 292-301. [CrossRef]

67. Landsat 8. Available online: https:/ / landsat.usgs.gov/landsat-8 (accessed on 1 January 2018).

68. United States Geological Survey (USGS). Landsat 8 (L8) Data Users Handbook; Department of the Interior U.S. Geological Survey: Washinton, DC, USA, 2016; pp. 73-76.

69. Musacchio, M.; Amici, S.; Silvestri, M.; Teggi, S.; Buongiorno, M.F.; Silenzi, S.; Devoti, S. Application of CIRILLO: A new atmospheric correction tool on Castel Porziano Beach (CPB). Remote Sens. Environ. Monit. GIS Appl. Geol. VII 2007, 674935. [CrossRef]

70. Berk, A.; Bernsten, L.S.; Robertson, D.C. MODTRAN: A Moderate Resolution Model for LOWTRAN7; GL-TR-89-0122; Air Force Geophysics Laboratory: Hanscom AFB, MA, USA, 1989; p. 38.

71. Adler-Golden, S.M.; Matthew, M.W.; Bernstein, L.S.; Levine, R.Y.; Berk, A.; Richtsmeier, S.C.; Acharya, P.K.; Anderson, G.P.; Felde, G.; Gardner, J.; et al. Atmospheric correction for shortwave spectral imagery based on MODTRAN4. SPIE Proc. Imaging Spectrom. 1999, 3753, 61-69.

72. Vermote, E.F.; Tanre, D.; Deuze, J.L.; Herman, M.; Morcrette, J.J. Second Simulation of the Satellite Signal in the Solar Spectrum, 6S: An overview. IEEE Trans. Geosci. Remote Sens. 1997, 35, 675-686. [CrossRef]

73. Barsi, J.A.; Barker, J.L.; Schott, J.R. An Atmospheric Correction Parameter Calculator for a Single Thermal Band Earth-Sensing Instrument; Centre de Congres Pierre Baudis: Toulouse, France, 2003.

74. On Demand Surface Emissivity. Available online: https://lpdaac.usgs.gov/dataset_discovery/aster/aster_ products_table/ast_05 (accessed on 1 January 2018).

75. Sounding profiles. Available online: http://weather.uwyo.edu/upperair/sounding.html (accessed on 1 January 2018).

76. Zanter, K. Landsat 8 (L8) Data Users Handbook. Landsat Science Official Website. 2016. Available online: https:/ / landsat.usgs.gov/landsat-8-18-data-users-handbook (accessed on 20 January 2018).

77. Gillespie, A.; Rokugawa, S.; Matsunaga, T.; Cothern, J.S.; Hook, S.J.; Kahle, A.B. A temperature and emissivity separation algorithm for Advanced Spaceborne Thermal Emission and Reflection Radiometer (ASTER) images. IEEE Trans. Geosci. Remote Sens. 1998, 36, 1113-1126. [CrossRef]

78. Diliberto, I.; Cappuzzo, S.; Inguaggiato, S.; Cosenza, P. Instrumental system for the quick relief of surface temperatures in fumaroles fields and steam heated soils. Geophys. Res. Abstr. 2014, 16.

79. Cappuzzo, S.; Cosenza, P.; Gagliano, A.L.; Diliberto, I.S. Sviluppo di un sistema strumentale per il rilievo speditivo della temperatura su superfici esposte. Rapporti Tecnici INGV 2015, 316, 1-26.

80. Francis, P.W. Infra-red techniques for volcano monitoring and prediction-A review. J. Geol. Soc. Lond. 1979, 136, 355-359. [CrossRef]

81. Dozier, J. A method for satellite identification of surface temperature fields of subpixel resolution. Remote Sens. Environ. 1981, 11, 221-229. [CrossRef]

82. Calvari, S.; Lodato, L.; Spampinato, L. Monitoring Active Volcanoes Using a Handheld Thermal Camera. In Proceedings of the SPIE Thermosense XXVI, Orlando, FL, USA, 13-15 April 2004; Volume 5405, pp. 199-209.

83. Calvari, S.; Spampinato, L.; Lodato, L.; Harris, A.J.L.; Patrick, M.; Dehn, J.; Burton, M.R.; Andronico, D. Chronology and complex volcanic processes during the 2002-2003 flank eruption at Stromboli volcano (Italy) reconstructed from direct observations and surveys with a handheld thermal camera. J. Geophys. Res. 2005, 110, B02201. [CrossRef]

84. Ball, M.; Pinkerton, H. Factors affecting the accuracy of thermal imaging cameras in volcanology. J. Geophys. Res. 2006, 111, B11203. [CrossRef]

85. Sawyer, G.M.; Burton, M.R. Effects of a volcanic plume on thermal imaging data. Geophys. Res. Lett. 2006, 33, L14311. [CrossRef]

86. Harris, A.J.L. Thermal Remote Sensing of Active Volcanoes: A User's Manual; Cambridge Press: Cambridge, UK, 2013.

87. Stevenson, J.A.; Varley, N. Fumarole monitoring with a handheld infrared camera: Volcán de Colima, Mexico, 2006-2007. J. Volcanol. Geotherm. Res. 2008, 177, 911-924. [CrossRef] 
88. Historical meteorological data on Vulcano island. Available online: https://oplao.com/it/weather (accessed on 1 January 2018).

89. Colini, L.; Spinetti, C.; Lombardo, V.; Buongiorno, M.F.; Diliberto, I.S.; Pecoraino, G.; Brusca, L.; Guida, R.; Cafaro, P.; Liardo, S.; et al. La campagna di telerilevamento alle isole Eolie: Validazione dei dati acquisiti da un sensore aereo multispettrale. Rapporti Tecnici INGV 2012, 241, 1-30.

90. Silvestri, M.; Diaz, J.A.; Vita, F.; Musacchio, M.; Puchalla, J.; Falcone, S.; Buongiorno, M.F.; Doumaz, F.; Wright, K. Improved instruments for volcanic plume observation for monitoring purpose: Solfatara and Vulcano island preliminary result. Rapporti tecnici INGV 2016, 349, 1-44.

91. Diliberto, I.S. INGV-DPC Project V3_5-Vulcano Section 2. Rep. Individ. Res. Units 2007, 1, 1-7.

92. Kneizys, F.X.; Shettle, E.P.; Gallery, W.O.; Chetwynd, J.H., Jr.; Abreu, L.W.; Selby, J.E.A.; Clugh, S.A.; Fenn, R.W. Atmospheric trasmittance/radiance: Computer code LOWTRAN 6. In Environmental Research Paper; Air Force Geophys. Lab.: Hanscom AFB, MA, USA, 1983.

2019 by the authors. Licensee MDPI, Basel, Switzerland. This article is an open access article distributed under the terms and conditions of the Creative Commons Attribution (CC BY) license (http://creativecommons.org/licenses/by/4.0/). 